\title{
Bi-Level Phase Load Balancing Methodology with Clustering-Based Consumers' Selection Criterion for Switching Device Placement in Microgrids
}

\author{
Gheorghe Grigoraș ${ }^{1, *}$, Bogdan-Constantin Neagu ${ }^{1}$, Florina Scarlatache ${ }^{1}$, Livia Noroc ${ }^{1}$, and \\ Ecaterina Chelaru ${ }^{1}$ \\ 1 Department of Power Engineering; "Gheorghe Asachi” Technical University of Iasi, Romania, \\ ggrigor@tuiasi.ro (G.G.); bogdan.neagu@tuiasi.ro (B.C.N.); florina.scarlatache@academic.tuiasi.ro (F.S.); \\ livia.grimailo@student.tuiasi.ro (L.N.); ecaterina.chelaru@student.tuiasi.ro (E.C.) \\ * Correspondence: ggrigor@tuiasi.ro;ghgrigoras@yahoo.com Tel.: +04 0232278683 (G.G.)
}

\begin{abstract}
In the last years, the Distribution Grid Operators (DGOs) assumed transition strategies of the distribution grids towards an active area associated with the "Smart Grids" concept. They are considering the use of Artificial Intelligence techniques, combined with advanced technologies and real-time remote communication solutions of the enormous data amounts, to develop smart solutions into the small size distribution grids, also called microgrids $(\mu \mathrm{Gs})$. These solutions will provide support for the DGOs to ensure an optimal operation of the technical infrastructure of the $\mu \mathrm{Gs}$. In this context, a bi-level methodology for solving the phase load balancing problem in the $\mu$ Gs with complex topologies and a high number of single-phase consumers, considering a clustering-based selection criterion of the consumers for placement of the switching devices, was proposed in the paper. A real $\mu \mathrm{G}$ from a rural area, with 114 consumers integrated into the Smart Metering System (SMS), belonging to the DGO from Romania, was considered in testing the proposed methodology. An implementation degree of $17.5 \%$, corresponding to the phase load balancing equipment installed to only 20 consumers from the $\mu \mathrm{G}$, led to a faster computational time with $43 \%$ and reducing the number of switching operations by $92 \%$ than in the case of a full implementation degree $(100 \%)$. The performance indicators related to the unbalance factor and energy-saving used in the evaluation of the technical benefits highlighted the efficiency of the proposed methodology.
\end{abstract}

Keywords: microgrids; phase load balancing; consumers' selection criterion; switching devices; unbalance factor; energy-saving.

\section{Introduction}

Today, the transformation of the technical infrastructure that to satisfy the requirements of the small size active distribution grids, namely microgrids $(\mu G s)$, is technically possible due to the presence of the automation devices and, more recently, smart meters that communicate using industry standards. On the other hand, there are challenges of the Distribution Grid Operators (DGOs) to ensure the transition towards the $\mu$ Gs: the emergence of the distributed generation sources (including the prosumers) and storage systems, the requirements for reducing the carbon footprint of electricity production that determines the change of the market model, and the presence of the bidirectional power flow [1].

In the current stage of this transition, the accelerated development in innovation and technology plays an important role leading to [2]:

- investments in the technical infrastructure of the actual electricity distribution grids to achieve flexibility able to adapt to new requirements of the $\mu \mathrm{Gs}$;

- increasing the automation degree in the $\mu \mathrm{Gs}$ to ensure the resilience, optimal integration of the distributed generation sources, efficient solutions for an optimal operation; 
- optimization of the topology to ensure the continuity in the energy supply of the consumers.

In this context, the directions assumed by the DGOs aim to bring the distribution grids from the passive area in an active area, where Artificial Intelligence techniques, combined with advanced technologies and real-time remote communication solutions of the enormous data amounts, led to the development of the concepts, equipment, technologies, and solutions associated with the "smart grids" concept. The manufacturers of the automation equipment/devices are focused on adaptable and reliable solutions with secure communication systems to ensure interconnectivity with the Smart Metering System (SMS) of the DGOs. The possibilities of the advanced technologies and the dedicated platforms offer new opportunities to the equipment manufacturers to develop new architectures of the smart systems, including the sensors, meters, data concentrators, and automation devices that can communicate with each other to ensure a high level of intelligence of the $\mu$ Gs. These systems will provide support for an optimal operation of the technical infrastructure [2].

One of the issues from the operation of the $\mu \mathrm{Gs}$ that can be solved using these smart systems refers to the phase load balancing (PLB). Ideally, the $\mu$ Gs should operate in a symmetric and balanced regime. In real conditions, such an ideal operating associated with the current and voltage system is practically impossible due to the dynamic variation of the load absorbed by the single-phase (1-P) consumers. In these conditions, the operation regime of the $\mu \mathrm{Gs}$ becomes unbalanced, affecting the three-phase symmetry of voltage and current, with economic and technical losses for the DGO.

Currently, various solutions have been developed in the literature to solve the PLB problem. They consider the following objectives: the minimization of the damages to the consumers, minimization of the unbalance degree and the maximization of the energy-saving. The optimal allocation of single-phase (1-P) consumers has started to be studied more deeply lately due to the implementation of the SMS concept. Generally, many references from the literature refer to different variants of the PLB mechanisms. For example, [3]-[5] have investigated the PLB problem based on the automatic 1-P consumer allocation. The phase reconfiguration, or consumer reallocation, can be automatically operated to minimize the current unbalance [3] based on the specific devices with controllable switches connected on the low voltage (LV) side of the supply point (SP), identified through the electric substation connected to the medium voltage (MV) electricity distribution grid of the DGO. If at least one phase is overloaded, one relay switches one or more consumers on the other two through a micro-controller [4] or an active phase router [5]. A simple $\mu G$, such as a residential house or experimental laboratory test diagram, was used in testing the last two solutions.

On the other side, many researchers considered the minimization of power losses by manual reallocation of the 1-P consumers on the LV three phases, as a result of different proposed approaches which can be applied only on the off-line operation mode [6]-[8]. The main disadvantage of these methodologies is the reallocation of all consumers in the $\mu \mathrm{Gs}$ that cannot be achieved simultaneously, leading to additional power losses. The solution proposed in [8] has focused on the minimization of active power loss, considering a minimum number of selected 1-P consumers for swapping between the three phases of the grid. The optimal allocation of reactive power devices will not solve the PLB problem [7], [9]. Also, the three-phase capacitor allocation led to high costs in the $\mu \mathrm{Gs}$. In another perspective, the historical information about load balance can decrease the unbalance factor by more than $10 \%$, only if the solution related to the allocation of the consumers on the phases is optimal [10].

Other analyses use the metaheuristics algorithms that tend to be considered less intricate for implementation: discrete Genetic Algorithm [6], [11], Particle Swarm Optimization Algorithm [8], Gray Wolf Optimization Algorithm [12], Flower Pollination Algorithm [13], Ant Colony Optimization [14], or Nelder Mead combined with Bacterial Foraging Algorithm [15]. Most of these researches report that the performed studies aim to reach the global optimum. This observation is never correct for a heuristic method that runs on the real $\mu \mathrm{Gs}$. At the same time, the computation time increases with the complexity of the problem.

The new challenges of the DGOs are related to the large-scale integration of the prosumers, storage systems, and electric vehicles. In this context, the PLB problem sparked, again, a particular interest of researchers. The authors have implemented in [16] a power market mechanism with financial benefits to encourage both consumers and local producers to participate in the PLB process. 
The balancing mode (using switching devices or manually) is missing because due to commercial objectives subject to some technical constraints.

The approaches from [17] - [19] studied the PLB problem considering the integration of electric vehicles. Kikhavani M.R. et al. in [17] addressed the optimal phase connection of Plug-in electric vehicles (PEVs) based on the power loss minimization and the improvement of the voltage profile. The algorithm commands phase switching devices, which connect or disconnect the optimal number of PEVs in the two operational ways (vehicle-to-grid and grid-to vehicle). Reference [18] presents the adaptive coordination between the photovoltaic inverters and electric vehicle charger based on a local controller device to solve the PLB problem. At the same time, the approach detailed in [19] proposed the LV modular bypass converters. The main advantage of these active balancing methodologies refers to the particular topology of a $\mu \mathrm{G}$ without additional power losses. One of the options to address optimal phase balancing is the integration of energy storage systems in the $\mu G$ s with smallscale distributed generation, as in [20]. The main limitation of the last four approaches [17]-[20] is the balancing speed, which is limited to a high number of switching operations, as a consequence of the dynamic connection of the electric vehicle and storage systems. A comprehensive solution with smart transformers is presented in [21], while another study proposes a simple three-phase load balancing considering only the information provided by smart meters [22].

A brief description of the literature is presented in Table 1 to highlight the main contributions of the proposed methodology, considering the type of $\mu \mathrm{G}$, the balancing point (pillar/substation level), the balancing mode (manual/automatic), the optimization model with objective function (OF) with constraints $(\mathrm{C})$, and the minimum number of switching operations.

Table 1. The advantages of the proposed methodology vs. the literature.

\begin{tabular}{|c|c|c|c|c|c|c|c|c|c|}
\hline \multirow{2}{*}{$\begin{array}{c}\text { Authors, } \\
\text { Reference number }\end{array}$} & \multirow{2}{*}{$\begin{array}{l}\text { Type } \\
\text { of } \mu G\end{array}$} & \multirow{2}{*}{$\begin{array}{l}\text { The } \\
\text { consumer } \\
\text { selection } \\
\text { criterion }\end{array}$} & \multicolumn{2}{|c|}{$\begin{array}{c}\text { Balancing } \\
\text { Point }\end{array}$} & \multirow{2}{*}{$\begin{array}{l}\text { Balancing } \\
\text { Mode }\end{array}$} & \multicolumn{2}{|c|}{$\begin{array}{l}\text { Mathematic } \\
\text { model }\end{array}$} & \multicolumn{2}{|c|}{$\begin{array}{c}\text { Evaluation of } \\
\text { benefits }\end{array}$} \\
\hline & & & Pillar & $\begin{array}{l}\text { Sub- } \\
\text { station }\end{array}$ & & OF & C & $\begin{array}{l}\text { Switching } \\
\text { operations }\end{array}$ & $\begin{array}{l}\text { Energy } \\
\text { savings }\end{array}$ \\
\hline $\begin{array}{l}\text { Liu B. et al. [3] } \\
\text { Mahendran B. et al. [13] }\end{array}$ & Real & No & No & Yes & Automatic & UC & Yes & Yes & Yes \\
\hline $\begin{array}{l}\text { Haq S.U. et al. [4]; } \\
\text { Narayanan K.N. et. al. [5] }\end{array}$ & Test & No & No & No & Automatic & UC & No & No & No \\
\hline Homaee O. et al. [6] & Real & No & Yes & No & Manual & APL & Yes & No & Yes \\
\hline Liu Y.W. et al. [7] & Test & No & No & No & Mixed & UV & No & No & No \\
\hline $\begin{array}{l}\text { Kalesar B.M. [8] } \\
\text { Evzelman M. et al. [19] }\end{array}$ & Test & Yes & No & Yes & Automatic & APL & Yes & Yes & Yes \\
\hline Jianguo Z. et al. [9] & Test & No & No & No & Manual & $\mathrm{UC}$ & No & Yes & No \\
\hline $\begin{array}{l}\text { Arias J. et al. [10] } \\
\text { Al-Kharsan I. H. [12] }\end{array}$ & Test & No & No & Yes & Mixed & UF & No & No & Yes \\
\hline $\begin{array}{l}\text { Echeverri G.M. et al. [11] } \\
\text { Faessler B., et al. [20] }\end{array}$ & Test & Yes & No & No & Manual & APL & No & No & Yes \\
\hline $\begin{array}{l}\text { Saffar A. et al. [14] } \\
\text { Hooshmand R. et al. [15] }\end{array}$ & Test & Yes & Yes & No & Manual & APL & Yes & No & Yes \\
\hline Olek B. et al. [16] & Test & No & No & No & Non & UV & No & No & No \\
\hline $\begin{array}{l}\text { Kikhavani M.R. et al. [17] } \\
\text { Weckx S. et al. [18] }\end{array}$ & Test & No & No & Yes & Automatic & APL & Yes & No & No \\
\hline $\begin{array}{l}\text { De Carne G. et al. [21] } \\
\text { Pasdar A. et al. [22] }\end{array}$ & Test & Yes & No & Yes & Automatic & UC & Yes & No & No \\
\hline Proposed methodology & Real & Yes & Yes & Yes & Automatic & UF & Yes & Yes & Yes \\
\hline
\end{tabular}

The objective function considers the minimization of unbalance current (UC), unbalance voltage (UV), unbalance factor (UF), cost optimization (CO), and active power losses (APL). Many other papers in the literature solve the PLB problem, but the approaches coincide with those presented in Table 1. 
The proposed methodology includes the following original contributions:

- the use of the K-means algorithm-based clustering in the first level to select the "candidate" groups containing 1-P consumers where the phase load balancing equipment (PLBE) are installed, with a significant influence on the minimization of unbalance factor; the clustering simplify the selection process leading at a relatively small number of 1-P consumers with the PLBE installed;

- the use of an improved PLB algorithm in the second level that aims minimization of the unbalances factor at the SP level, subject to the constraints where its value must be below an imposed limit by the Decision-Maker (DM) at the pillars with 1-P consumers from the "candidate" groups connected.

Section 3 will present the details on these contributions.

The organization of the next sections is the following: Section 2 presents the architecture of a Smart Balancing System (SBS) which can solve the PLB problem efficiently, Section 3 particularizes the levels of the proposed methodology which integrates the clustering-based selection criterion of the consumers for the PLB process, Section 4 details the results obtained for a real $\mu G$ from the northeastern area of Romania and a comparison with the methodology where all consumers take part to the PLB process (100\% implementation degree of the PLBE) to highlight the accuracy and benefits of the proposed algorithm, and Section 5 includes the conclusions and the future works.

\section{The Architecture of the Smart Balancing System}

The architecture of an SBS used in solving the PLB problem from a $\mu$ should have the following main components: the phase load balancing equipment (PLBE), composed of a smart meter (SM) and a switching device (SD), a high-speed data communication system, and the data concentrator from the supply point (SP), See Fig. 1. All 1-P consumers must have the three-phase (3-P) branching (where $a b c$ represents the phase conductors and $\mathrm{N}$ is associated with the neutral conductor) to be involved in the PLB process.

The PLBE is installed in the consumption points where there is a 3-P branching. The data concentrator installed in the SP takes over, with a sampling step (15, 30, or 60 minutes) set by the DM, the data on the current and the connection phase from each consumption point associated with the 1-P consumer.

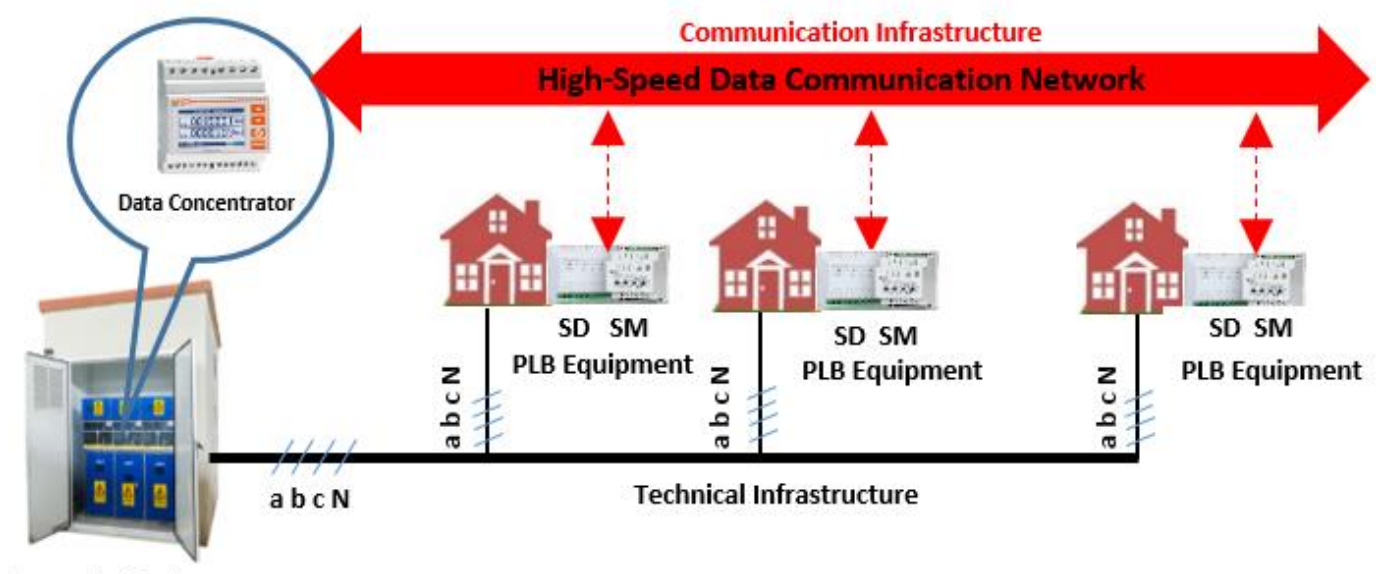

Supply Point

Fig. 1. The architecture of the SBS used in the PLB process 


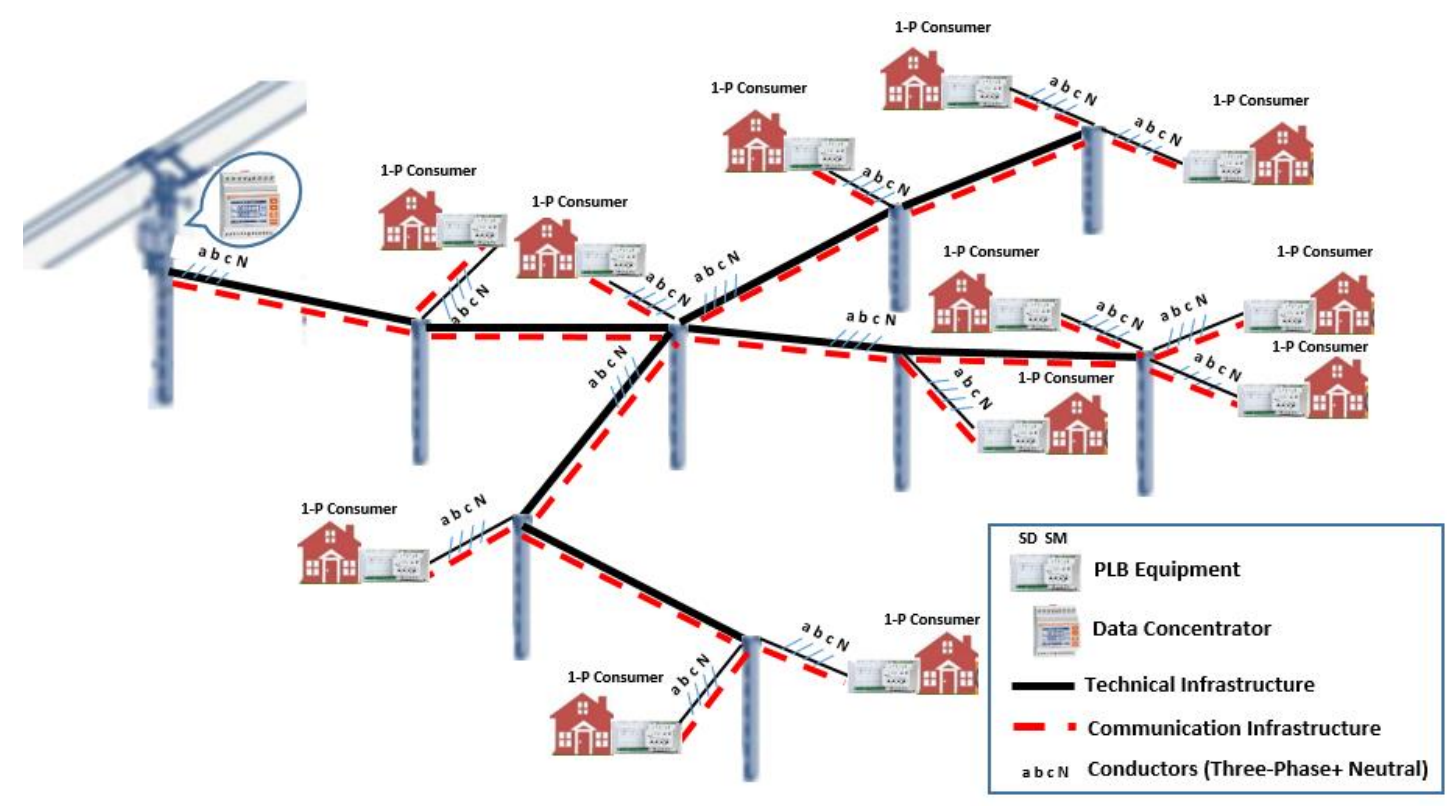

Fig. 2. The structure of a generic $\mu \mathrm{G}$ with the SBS installed (100\% implemented degree)

The decision-making module, which includes the PLB algorithm, processes the data, and finally, sends the command to each SD to switch the load on the new phase according to the identified solution corresponding to a minimum unbalance degree.

Fig. 2 presents the implementation of the SBS in a $\mu \mathrm{G}$ where all 1-P consumers have 3-P branching and the PLBE installed (100\% implementation degree).

Regarding the first component (SD) of the SBS, there are different approaches proposed in many research papers based on a high automation degree. The Static Transfer Systems (STS)-based devices, with various costs and technical performances [23]-[25], were already implemented. These solutions follow reducing the purchase cost and switching times. Other devices use a control system of the three-phase load unbalance [26] composed of a magnetic holding relay and a thyristor in parallel that allows quickly switching the load between phases $a, b$, or $c$. The main advantages of this solution are low cost, high real-time performance, and a positive effect on reducing the unbalance factor. An automatic phase load balancing device, based on a microcontroller and three relays, was proposed in the references [27] - [29]. The operating time of the relay represents a significant technical parameter in the switching process. The results indicated that this solution is efficient, having a reduced cost in their implementation. Another variant of a three-phase balancing device is presented in [30] that has in their structure six relays and six contactors to ensure the balanced regime of three controllable loads. The conclusion is that increasing the loads can lead to a high cost due to the number of contactors. The solid-state relays and contactors connected to each phase represent the base of the solution adopted in [31]. The three triacs of relays operate such that no two triacs are in the "on state" at the same time because this state will create a short circuit among phases. A design of a phaseswapping device with magnetic latching relays (MLRs) proposed in [32] can represent an efficient solution having economic and technical benefits. Currently, the price of three magnetic latches with a maximum load of $100 \mathrm{~A}$ on the market is less than 30 , while the price of MLRs is usually more than $100 \$$. In these conditions, this device can lead to a reduction of the cost of the equipment and realize the functions of zero-voltage turn-on and zero-current turn-off, which reduce the impact of inrush current and arc on the user. Also, it uses a high-speed data transmission system that is the main advantage in the implementation of a remote control scheme.

But, the architecture of the SBS can have a significant impact on the operation of the $\mu$ Gs only if the following requirements are fulfilled: the communication infrastructure has a high-speed data transmission, the data concentrator located at the level of the SP, which integrates the decisionmaking module, has superior performances (high data acquisition and processing speed), and the SD 
performs fast switching between phases of the 1-P consumers. However, a compromise must be between these requirements leading to a convenient cost for the DGO.

\section{Methodology}

The proposed methodology, associated with the optimal placement of the PLBE in the consumption places, is built considering two hierarchical levels of the decision making process. The flow-chart of the methodology applied is shown in Fig. 3.

\subsection{The first level - Identification of the consumers" "candidate" groups}

The first level refers to a decision-making process where the consumers' "candidate" groups with PLBE installed are established based on the clustering process. The choice of the K-means algorithm in the clustering process was due to the following advantages: comparatively easy to be implemented, works with the high-size database, ensures convergence, can quickly initialize the positions of centroids, and effortlessly accommodates to new samples [33], [34].

\section{START}

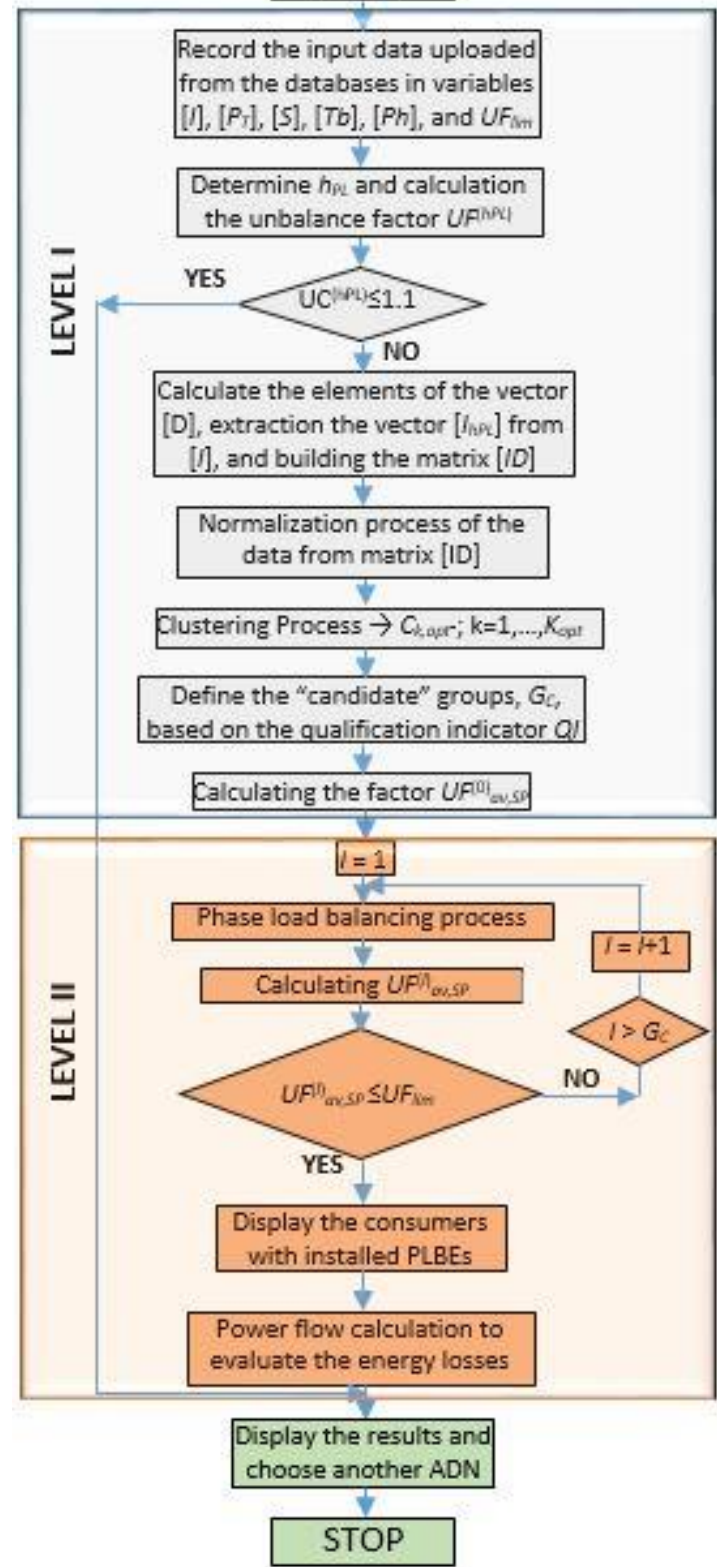

Fig. 3. The flow-chart of the proposed methodology 


\subsubsection{Input data}

The input data considered in the clustering process include for each consumer $n, n=1, \ldots, N_{c}$, where $N_{c}$ represents the total number of the consumers, the absorbed current at the hour when the peak load, $h_{P L}$, was recorded in the $\mu \mathrm{G}$, and the distance, $D_{n}, n=1, \ldots, N_{C}$, from the SP (connected to the MV electricity distribution grid of the DGO) to the pillar where the consumer is connected. Thus, the consumers subjected to the clustering process have these features recorded in a matrix $I D$, having the size Ncx2:

$$
[I D]_{N_{C} x 2}=\left[\begin{array}{cc}
I_{1, h_{P L}} & D_{1} \\
\vdots & \vdots \\
I_{n, h_{P L}} & D_{n} \\
\vdots & \vdots \\
I_{N_{C}, h_{P L}} & D_{N_{C}}
\end{array}\right]
$$

where: $N_{c}$ represents the number of the consumers from the $\mu \mathrm{G}$ integrated in the SMS; $h_{P L}$ is the hour when the peak load was recorded in the $\mu \mathrm{G} ; I_{n, h P L}$ corresponds the absorbed current by the consumer $n, n=1, \ldots, N_{C}$ at the hour $h_{P L} ; D_{n}$ indicates the distance between the SP and the pillar where the consumer $n$ is connected.

The current profiles corresponding to the day of the peak load from the $\mu \mathrm{G}$ are uploaded from the database of the SMS in a matrix [I], having the size NcxH:

$$
[I]_{N_{C} x H}=\left[\begin{array}{ccccc}
I_{1,1} & \cdots & I_{1, h} & \cdots & I_{1, H} \\
\vdots & \vdots & \vdots & \vdots & \vdots \\
I_{n, 1} & \cdots & I_{n, h} & \cdots & I_{n, H} \\
\vdots & \vdots & \vdots & \vdots & \vdots \\
I_{N_{C}, 1} & \cdots & I_{N_{C}, h} & \cdots & I_{N_{C}, H}
\end{array}\right]
$$

where and $H$ is the analysed time period (in this case $H=24$ hours, with a sampling step $\Delta h=1$ hour).

The aggregation of these profiles at the LV level of the SP to identify the hour of the peak load represents the following step:

$$
\begin{gathered}
{\left[I^{(S P)}\right]_{1 x H}=\left[\sum_{n=1}^{N_{C}} I_{n, 1}^{(S P)} \ldots \sum_{n=1}^{N_{C}} I_{n, h}^{(S P)} \ldots \sum_{n=1}^{N_{C}} I_{n, H}^{(S P)}\right]} \\
\left\lfloor I_{\max }^{(S P)}, h_{P L}\right\rfloor=\max _{h}\left\{\left\lfloor I^{(S P)}\right\}\right\}
\end{gathered}
$$

where: $\left[I^{(S P)}\right] 1 \times H$ represents the vector of the currents aggregated at the LV level of the SP for each hour $h, h=1, \ldots, H ; h_{P L}$ is the hour when the maximum value of the total current (peak load) was determined from the vector $\left[I^{(S P)}\right] ; I^{(S P)} \max$ corresponds the maximum value of the total current (peak load) at the LV level of the SP.

The column $h_{P L}$ from the matrix [I], [ $\left.\mathrm{IhPL}_{\mathrm{L}}\right]$, will be used in the clustering process as the first feature of the consumers, representing the absorbed currents at the hour when the peak load has been recorded in the $\mu \mathrm{G}$.

In addition to the current profiles, the branching type, $t_{b}, t_{b}=\{1-P, 3-P\}$, where 1-P is associated with the single-phase consumers and 3-P with the three-phase consumers, and connection phase, $p=\{a, b, c, a b c\}$, for each consumer, are uploaded from the consumers' database of the DGO based on the identification number of the analysed $\mu \mathrm{G}$ and recorded in the vectors $[\mathrm{Tb}]_{1 \times N c}$ and $[P h]_{1 \times N c}$. The 1$\mathrm{P}$ consumers are connected at one of the phases $p=\{a, b, c\}$, and the 3-P consumers are connected at all three phases $p=\{a b c\}$. Based on these data, the current profiles are aggregated on each phase at the SP level, and the unbalance factor $(U F)$ is calculated for the peak load hour, $h_{P L}$, using the formula: 


$$
\begin{gathered}
U F^{\left(h_{P L}\right)}=\frac{1}{n_{p}} \cdot \sum_{p \in\{a, b, c\}}\left(\frac{I_{p}^{\left(h_{P L}\right)}}{I_{a v}^{\left(h_{P L}\right)}}\right)^{2} \\
I_{a v}^{\left(h_{P L}\right)}=\frac{I_{a}^{\left(h_{P L}\right)}+I_{b}^{\left(h_{P L}\right)}+I_{c}^{\left(h_{P L}\right)}}{n_{p}}
\end{gathered}
$$

where $p$ - the set of the phases $(p \in\{a, b, c\}) ; n_{p}$ corresponds the number of the phases $\left(n_{p}=3\right) ; I_{p}^{(h P L)}$ is the total current on the phase $p$, at the LV level of the SP and hour $h_{P L} ; I_{a v}{ }^{(h P L)}$ - the average value of the phase currents at the SP level and hour $h_{P L}$.

If $U F^{(h P L)}$ has a value higher than 1.1 (limit value accepted by the DGO for the unbalance factor), the clustering algorithm is initialized to identify the consumers' "candidate" groups.

The second column of the matrix $[I D]$, corresponding to the second feature used in the clustering process, refers to the distances between the pillars and the SP. The calculation of these distances is easy, knowing the topology of the $\mu \mathrm{G}$ identified based on an algorithm proposed by the authors in [35]. Fig. 4 explains the synthesis of the approach.

The two structure-vectors, [VT1] and [VT2], identifies the topology of the $\mu \mathrm{G}$. The consecutive grouping of the distribution sections between two pillars to a connecting stage represents the starting point in the building of the two vectors. The notations are the following: for the connecting stage CS1 ... CS4, the sections $S 1 \ldots S 8$, pillars $P 1 \ldots P 8$, and consumers $C 1 \ldots C 10$. The data related to the

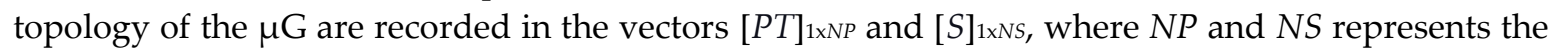
total number of the pillars and sections. The connected phases $(a, b$, or $c)$ of the consumers have indicated between the round brackets. The values of the elements associated with the vectors [VT1] and [VT2] are under the single-line diagram of the $\mu \mathrm{G}$.

Using this topology and the additional information obtained from the DGO regarding the distance between two successive pillars, which is $0.04 \mathrm{~km} \mathrm{[36],} \mathrm{a} \mathrm{distance-vector} \mathrm{[D]1xNc,} \mathrm{having} \mathrm{the}$ size $1 \times N C$, is built knowing the allocation of the consumers to the pillars. The elements of this vector, associated with the topology from Fig. 4, are presented in Table 2.

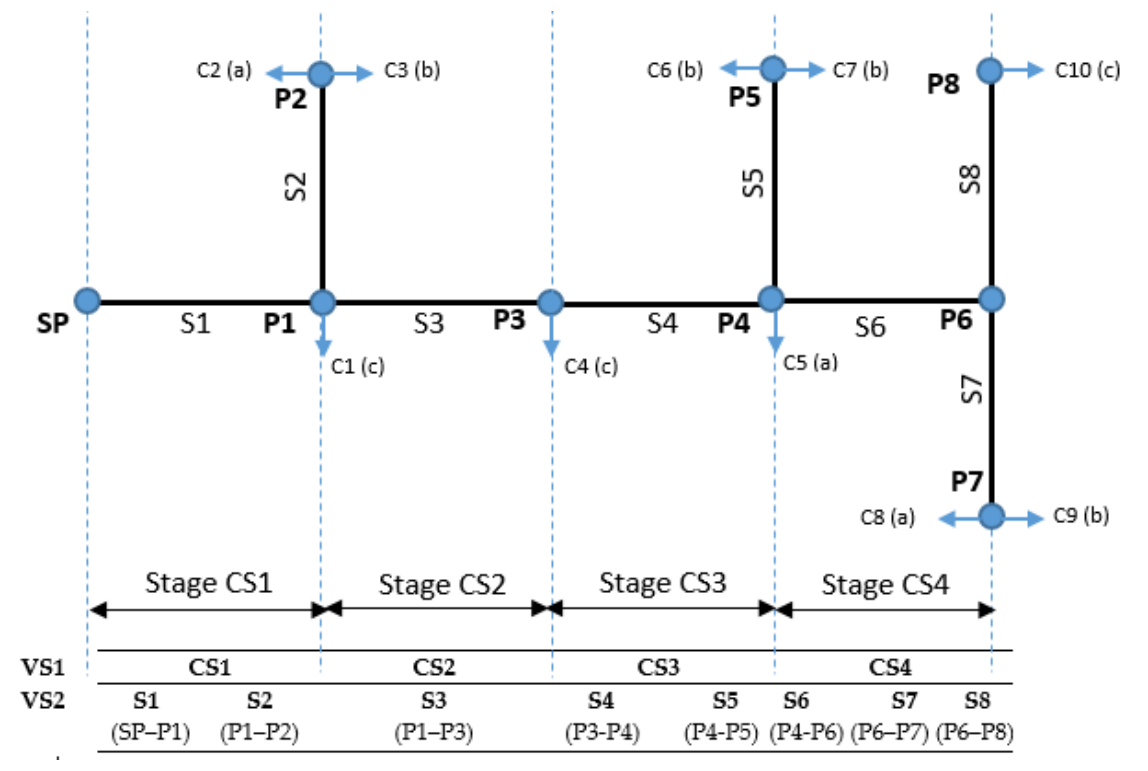

Fig. 4. The exemplification of the structure vectors-based approach

Table 2. The allocation of the consumers to the pillars and the distances to the SP (see Fig. 4)

\begin{tabular}{ccccccccccc}
\hline Pillar & P1 & \multicolumn{2}{c}{ P2 } & P3 & P4 & \multicolumn{2}{c}{ P5 } & \multicolumn{2}{c}{ P7 } & P8 \\
\hline Consumer & C1 & C2 & C3 & C4 & C5 & C6 & C7 & C8 & C9 & C10 \\
Phase & c & a & b & c & a & b & b & a & b & c \\
Distance, $[\mathrm{km}]$ & 0.04 & 0.08 & 0.08 & 0.08 & 0.12 & 0.16 & 0.16 & 0.20 & 0.20 & 0.20 \\
\hline
\end{tabular}


The vector $[D]$ represents the second feature of the consumers used in the clustering process (the second column from matrix [ID]).

The normalization of the features represented by the elements of the vectors $\left[\mathrm{IhPL}_{\mathrm{L}}\right]$ and $[D]$ corresponds to the last stage before starting the clustering process. The following relations represent the base of the normalization stage [37]:

$$
\begin{aligned}
I_{n, h_{P L}}^{*} & =\frac{I_{n, h_{P L}}-I_{h_{P L}, \max }}{I_{h_{P L}, \max }-I_{h_{P L}, \min }} ; D_{n}^{*}=\frac{D_{n}-D_{\max }}{D_{\max }-D_{\min }} \quad n=1, \ldots, N_{C} \\
I_{h_{P L}, \max } & =\max _{n=1, . ., N_{C}}\left\{I_{n, h_{P L}}\right\} ; I_{h_{P L}, \min }=\min _{n=1, . ., N_{C}}\left\{I_{n, h_{P L}}\right\} \\
D_{\max } & =\max _{n=1, \ldots, N_{C}}\left\{D_{n}\right\} ; D_{\min }=\min _{n=1, ., N_{C}}\left\{D_{n}\right\}
\end{aligned}
$$

where $I_{n, h_{P L}}^{*}$ represents the normalized value of the absorbed current by the consumer $n, n=1, \ldots, N_{c}$ at the hour $h_{P L} ; D_{n}^{*}$ is the normalized value of the distances between the pillar to which the consumer $n$ is connected and the SP; $I_{h P l, m i n}$ and $I_{h P L, m a x}$ correspond the minimum and maximum values of the absorbed currents at the hour $h_{P L}$; $D_{\min }$ and $D_{\max }$ indicate the minimum and maximum values determined from all distances calculated for the consumers.

\subsubsection{Clustering process}

The K-means algorithm receives as input data the normalized matrix $\left[I D^{*}\right]_{N c x 2}$ (see relation 1), where each row $\left[I D_{n}^{*}\right]=\left[\begin{array}{ll}I_{n, h P L}^{*} & D^{*}\end{array}\right]$ is associated with a consumer $n=1, \ldots, N_{c}$, having as features the absorbed current $I_{n, h_{P L}}^{*}$ at the hour when the peak load, $h_{P L}$, was recorded in the $\mu \mathrm{G}$, and the distance, $D_{n}^{*}, n=1, \ldots, N_{c}$, from the SP to the pillar where the consumer is connected.

The objective of the $\mathrm{K}$-means algorithm is grouping the consumers in $K$ clusters denoted by $C=$ $\left\{C_{k} \mid k=1: K\right\}$. The grouping is performed in such a way as to minimize the objective function:

$$
F(I D, K)=\sum_{k=1}^{K} \sum_{\substack{I D_{n} \\ n=1, \ldots, N_{C}}} \operatorname{dist}\left(I D_{n}^{*}, m_{k}\right)
$$

where: $m_{k}$ is the centroid of the cluster $k, k=1, \ldots, K$; dist $(.$, . $)$ represents the Euclidean distance in the two-dimensional space.

The algorithm starts with a random set of the centroids associated with the $K$ clusters and then change the centroids into several iterations. Finally, it will find a partition that corresponds to a minimum of the function $F$ [38].

The main steps of the algorithm are the following, see Fig. 5:

Initialization: It starts with the random selection of the $K$ centroids from the rows of the matrix $[I D]$ :

$$
M=\left\{m_{1} 1^{(0)}, \ldots, m_{k}^{(0)}, \ldots, m_{K^{(0)}}\right\}
$$

Assigning: Each row from the input data matrix is associated with the nearest centroid:

$$
I D_{n}^{*} \in C_{k} \text { if } \min _{k}\left\{\operatorname{dist}\left(I D_{n}^{*}, m_{k}\right)\right\}
$$

Update: The new positions of the centroids $m_{k}, k=1, \ldots, K$, are recalculated as the average of the features (current and distance) associated with the consumers from that cluster $C_{k}$.

The following formula sums up all the characteristics of the consumers belonging to the cluster $C_{k}, k=1, \ldots, K$, having the membership degree to it.

$$
m_{k}=\frac{1}{n_{k}} \sum_{\substack{I D_{n} \in C_{k} \\ n=1, \ldots, N_{C}}} I D_{n}^{*}, \quad k=1,2, \ldots, K
$$

where $n_{k}$ is the number of consumers from the cluster $C_{k}$. 


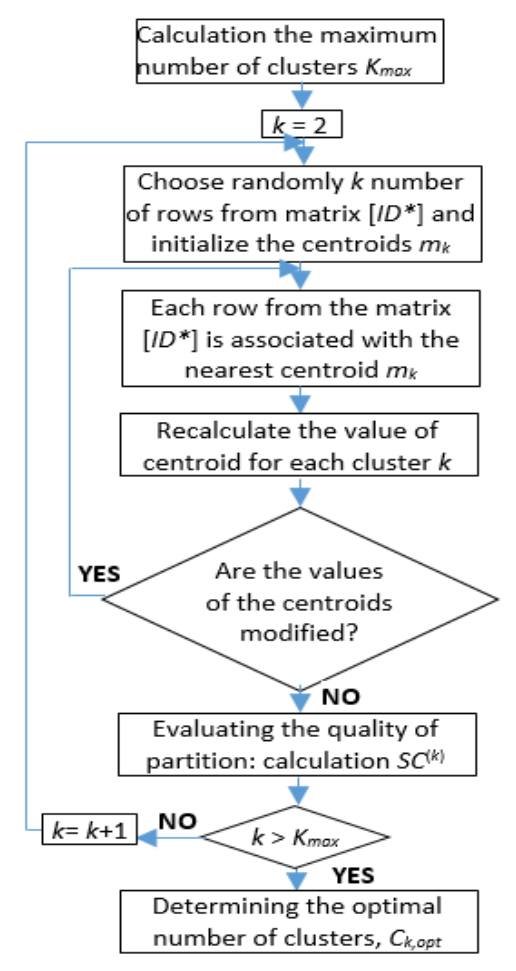

Fig. 5. The steps of the clustering process

Stopping: Steps 2 and 3 (Assigning and Update) are repeated until a pass through the input data does not cause new assignments, and no change in the values of the centroids will not produce. Also, the maximum number of iterations of the algorithm can be limited.

But, the question is if the algorithm found a partition that corresponds to a global optimum of the function $F$. To obtain the optimal number of clusters the following steps can be completed:

- Calculation the maximum number of clusters based on the formula [37]:

$$
K_{\max }=\sqrt{N_{C}}
$$

- Clustering: K-means clustering method is used for each partition in the $C_{k}$ clusters, $k=2, \ldots, K_{\max }$, using the input data matrix.

- Evaluating the quality of partition: The evaluation is based using the silhouette coefficient calculated with the relation [39]:

$$
\begin{gathered}
S C^{(K)}=\frac{1}{N_{C}} \sum_{n=1}^{N_{C}}\left(\frac{b_{i}-a_{i}}{\max \left\{a_{i}, b_{i}\right\}}\right) \\
\sum_{\substack{j \in r \\
j \neq i}} \operatorname{dist}\left(I D_{i}^{*}, I D_{j}^{*}\right) \quad ; \quad b_{i}=\min _{s \neq r} \frac{\sum_{\substack{j \in S \\
j \neq i}} \operatorname{dist}\left(I D_{i}^{*}, I D_{j}^{*}\right)}{N_{r}-1}
\end{gathered}
$$

where : $N_{r}$ and $N_{s}$ are the number of the consumers assigned to the clusters $r$ and $s$; $\operatorname{dist}\left(I D_{i}, I D_{j}\right)$ is the represents the Euclidean distance in the two-dimensional space between the $i$-th and $j$-th rows from the matrix $\left[I D^{*}\right]$.

- Iterative process: The steps 2 and 3 (Clustering and Evaluating the quality of partition) are repeated to evaluate the quality of partitions between 2 and $K_{\max }$. The values of $S C$ are recorded for each partition in the vector $Q P=\left[S C^{(2)}, S C^{(3)}, \ldots, S C^{(K m a x)}\right]$.

- Determining the optimal number of clusters through the calculation of the maximum value from the vector $Q P, S C_{\max }$. The partition with $S C_{\max }$ is associated with the optimal number of clusters, $C_{k, \text { opt. }}$

$$
\left[S C_{\max }, C_{k, o p t}\right]=\max _{K}\{[Q P]\}
$$




\subsubsection{Selecting the consumers' "candidate" groups}

The decision-making process to select the "candidate" groups uses a qualification indicator, QI, defined for the interest areas resulted from the zoning of the "distance-current" space. Each interest area has a degree of "importance", GI, (High, Medium, and Low) having a discrete value of the QI assigned. Thus, the interest areas cannot be similar mainly due to the differences associated with the distances between consumers and the SP from the rural and urban or aerial and underground $\mu \mathrm{Gs}$, and the absorbed currents at the peak load by the consumers.

Inside the interest areas, the consumers' groups associated with the clusters $C_{k, o p t}$, obtained from the clustering process are represented by the centroids $m_{k}$, with the average characteristics of the distances and absorbed currents of the consumers from each cluster.

The values of the $Q I$ depend on the degrees of importance: $G I \in\{7,8,9,10\}$, for a "High" degree, $\mathrm{GI} \in\{4,5,6\}$, for a "Medium" degree, and $\mathrm{GI} \in\{1,2,3\}$, for a "Low" degree. The clusters with the centroids inside the areas with a "High" degree of importance represent "candidate" groups. They will participate in the PLB process in descending order of the QI, and depending on the stop criterion imposed by the DM on the unbalance factor, $U F$, all or only some of them will be chosen.

The average value of the unbalance factor, UFav,SP, on the LV side of the SP, in the analysed period, $H$, is calculated in each iteration.

$$
U F_{a v, S P}^{(l)} \leq U F_{\text {lim }}, \quad 1=1, \ldots, G_{C}
$$

where:

$$
U F_{a v, S P}^{(l)}=\frac{\sum_{h=1}^{H} U_{a v, S P}^{(l, h)}}{H}
$$

where $l$ is the current iteration; Gc - number of "candidate" groups; UFlim - the specified value by the DM to stop the iterative process.

\subsection{The second level - phase load balancing process}

The PLB process is described by an algorithm having as aim the minimization of the unbalance factor, $U F$, on the LV side of the SP by switching the consumers assigned to the "candidate" groups from a phase to another. It represents an improved variant of the algorithm proposed in [40] where all consumers integrated into the SMS take part in the PLB process, having as the objective the minimization of the unbalance factor at each pillar. Even if the optimal solution corresponded to a value of the unbalance factor very close to 1.0 (ideal target), the number of switching operations is very high.

The improved variant of the algorithm starts with the end pillars and follows the route to the $\mathrm{SP}$, aggregating the currents on each phase. The objective is the minimization of the unbalance factor at the SP level. The constraints of the optimization model consider the values of the unbalance factor that must be smaller than an imposed limit by the DM at the level of the pillars with the 1-P consumers from the "candidate" groups connected. The optimal solutions are obtained through coordination of the PLBE installed to the consumers from the "candidate" groups, leading to a reduction of the time and switching operations.

Thus, the objective function of the PLB problem refers to the minimization of hourly unbalance factor inside the analysed period $H$ at the level of the SP:

$$
\min \left(U F_{S P}^{(h)}\right), \quad h=1, \ldots, H
$$

subject to:

$$
U F_{p_{G C}}^{(h)} \leq U F_{\lim }, \quad p_{G C} \in\left\{P_{G C} \subseteq P_{T}\right\}
$$

where: 


$$
\begin{aligned}
& U F_{S P}^{(h)}=\frac{1}{n_{p}} \cdot\left(\left(\frac{I_{a, S P}^{(h)}}{I_{a v, S P}^{(h)}}\right)^{2}+\left(\frac{I_{b, S P}^{(h)}}{I_{a v, S P}^{(h)}}\right)^{2}+\left(\frac{I_{c, S P}^{(h)}}{I_{a v, S P}^{(h)}}\right)^{2}\right) \\
& U F_{p_{G C}}^{(h)}=\frac{1}{n_{p}} \cdot\left(\left(\frac{I_{a, p_{C G}}^{(h)}}{I_{a v, p_{G C}}^{(h)}}\right)^{2}+\left(\frac{I_{b, p_{C G}}^{(h)}}{I_{a v, p_{G C}}^{(h)}}\right)^{2}+\left(\frac{I_{c, p_{C G}}^{(h)}}{I_{a v, p_{G C}}^{(h)}}\right)^{2}\right) \\
& I_{a v, S P}^{(h)}=\frac{1}{n_{p}}\left(I_{a, S P}^{(h)}+I_{b, S P}^{(h)}+I_{c, S P}^{(h)}\right) \\
& I_{a, S P}^{(h)}=I_{a, n s, S P}^{(h)}+I_{a, s, S P}^{(h)} ; \quad I_{b, S P}^{(h)}=I_{b, n s, S P}^{(h)}+I_{b, s, S P}^{(h)} ; \quad I_{c, S P}^{(h)}=I_{c, n s, S P}^{(h)}+I_{c, s, S P}^{(h)} \\
& I_{a, n s, S P}^{(h)}=\sum_{o=1}^{N_{a, n s}} I_{a, n s, o}^{(h)} ; \quad I_{b, n s, S P}^{(h)}=\sum_{f=1}^{N_{b, n s}} I_{b, n s, f}^{(h)} ; I_{c, n s, S P}^{(h)}=\sum_{v=1}^{N_{c, n s}} I_{c, n s, v}^{(h)} \\
& I_{a, s, S P}^{(h)}=\sum_{q=1}^{N_{a, s}^{(h)}} I_{a, s, q}^{(h)} ; \quad I_{b, s, S P}^{(h)}=\sum_{e=1}^{N_{b, s}^{(h)}} I_{b, s, e}^{(h)} ; \quad I_{c, s, S P}^{(h)}=\sum_{w=1}^{N_{c, s}^{(h)}} I_{c, s, w}^{(h)} \\
& n_{a}^{(h)}=N_{a, n s}+N_{a, s}^{(h)} \\
& n_{b}^{(h)}=N_{b, n s}+N_{b, s}^{(h)} \\
& n_{c}^{(h)}=N_{c, n s}+N_{c, s}^{(h)} \\
& N_{C}=n_{a}^{(h)}+n_{b}^{(h)}+n_{c}^{(h)} \\
& I_{a v, p_{G C}}^{(h)}=\frac{1}{n_{p}}\left(I_{a, p_{G C}}^{(h)}+I_{b, p_{G C}}^{(h)}+I_{c, p_{G C}}^{(h)}\right) \\
& I_{a, p_{G C}}^{(h)}=I_{a, n s, p_{G C}}^{(h)}+I_{a, s, p_{G C}}^{(h)}+I_{a, d}^{(h)}, \quad p_{G C} \in\left\{P_{G C} \subseteq P_{T}\right\} ; d \in\left\{P_{T}\right\} \\
& I_{b, p_{G C}}^{(h)}=I_{b, n s, p_{C G}}^{(h)}+I_{b, s, p_{G C}}^{(h)}+I_{b, d}^{(h)}, \quad p_{G C} \in\left\{P_{G C} \subseteq P_{T}\right\} ; d \in\left\{P_{T}\right\} \\
& I_{c, p_{G C}}^{(h)}=I_{c, n s, p_{G C}}^{(h)}+I_{c, s, p_{G C}}^{(h)}+I_{c, d}^{(h)}, \quad p_{G C} \in\left\{P_{G C} \subseteq P_{T}\right\} ; d \in\left\{P_{T}\right\} \\
& I_{a, n s, p_{G C}}^{(h)}=\left(\sum_{n_{i}=1}^{N_{a, n s, p}^{(h)}} I_{a, n s, n_{i}}^{(h)}\right) ; I_{b, n s, p_{G C}}^{(h)}=\left(\sum_{n_{j}=1}^{N_{b, n s, p_{C G}}^{(h)}} I_{b, n s, n_{j}}^{(h)}\right) ; I_{c, n s, p_{G C}}^{(h)}=\left(\sum_{n_{l}=1}^{N_{c, n s, p C G}^{(h)}} I_{c, n s, n_{l}}^{(h)}\right) \\
& I_{a, s, p_{G C}}^{(h)}=\left(\sum_{m_{i}=1}^{N_{a, s, p C G}^{(h)}} I_{a, s, m_{i}}^{(h)}\right) ; I_{b, s, p_{G C}}^{(h)}=\left(\sum_{m_{j}=1}^{N_{b, s, p C G}^{(h)}} I_{b, s, m_{j}}^{(h)}\right) ; I_{c, s, p_{G C}}^{(h)}=\left(\sum_{m_{l}=1}^{N_{c, s, p C G}^{(h)}} I_{c, s, m_{l}}^{(h)}\right) \\
& N_{C, n s, p_{G C}}^{(h)}=N_{a, n s, p_{G C}^{(h)}}^{(h)}+N_{b, n s, p_{G C}^{(h)}}^{(h)}+N_{c, n s, p_{G C}}^{(h)}
\end{aligned}
$$




$$
\begin{gathered}
N_{C, s, p_{G C}}^{(h)}=N_{a, s, p_{C G}}^{(h)}+N_{b, s, p_{G C}}^{(h)}+N_{c, s, p_{G C}}^{(h)} \\
N_{C, p_{G C}}^{(h)}=N_{C, n s, p_{G C}}^{(h)}+N_{C, s, p_{G C}}^{(h)}
\end{gathered}
$$

where: $U F_{S P}(h)$ - the unbalance coefficient on the LV side of the SP and hour $h ;\left\{P_{G C}\right\}$ - the set of the pillars with least one consumer from the "candidate" groups $G_{C}$ is connected; $\left\{P_{T}\right\}$ - the set of all pillars from the analyzed $\mu G ; U F_{p G C} C^{(h)}$ - the unbalance coefficient calculated for the hour $h$ at the pillar $p_{G C}$ where at least one consumer from the "candidate" groups $G_{C}$ is connected; UFlim - the limit value accepted by the DM for the unbalance coefficient at the pillar level; $I_{a, S P}{ }^{(h)}, I_{b, S P}(h), I_{c, S P}{ }^{(h)}-$ the currents on the phases $a, b$, and $c$ on the LV side of the SP and hour $h ; I_{a v, S P}(h)$ - the average value of the phase

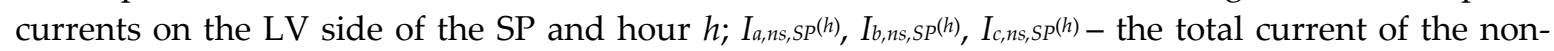
switchable consumers on the phases $a, b$, and $c$ on the LV side of the SP and hour $h ; I_{a, s, S P}(h), I_{b, s, S P}(h)$, $I_{c, s, S P}(h)$ - the total current of the switchable consumers on the phases $a, b$, and $c$ on the LV side of the SP and hour $h ; I_{a, n s, o}(h)$ - the current of the non-switchable consumer $o$ connected on the phase $a$ and hour $h$; $I b, n s, f^{(h)}$ - the current of the non-switchable consumer $f$ connected on the phase $b$ and hour $h$; $I_{c, n s, v}(h)$ - the current of the non-switchable consumer $v$ connected on the phase $c$ and hour $h$; $I_{a, s, q}(h)-$ the current of the switchable consumer $q$ connected on the phase $a$ and hour $h ; I_{b, s, e}(h)$ - the current of the switchable consumer $e$ connected on the phase $b$ and hour $h ; I_{c, s, w}(h)$ - the current of the switchable consumer $w$ connected on the phase $c$ and hour $h ; I_{a, p G C}(h), I_{b, p G C}(h), I_{c, p G C}(h)-$ the currents on the phases $a, b$, and $c$, at the pillar $p_{G C} \subseteq\left\{P_{G C}\right\}$ and hour $h ; I_{a v, p C G}(h)$ - the average value of the phase currents at the pillar $p_{C G} \subseteq\left\{P_{G C}\right\}$ and hour $h ; I_{a, d}(h), I_{b, d}(h), I_{c, d}(h)$ - the currents on the phases $a, b$, and $c$, at the pillar $d \subseteq\left\{P_{T}\right\}$

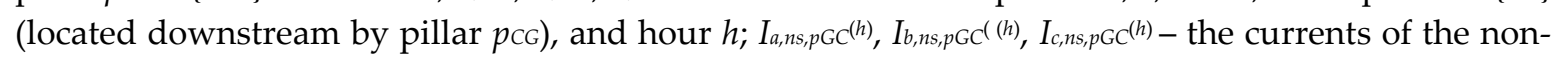

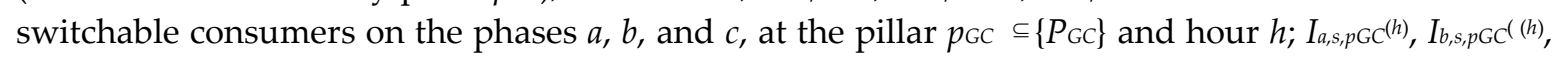
$I_{c, s, p G C^{(h)}}$ - the currents of the switchable consumers on the phases $a, b$, and $c$, at the pillar $p_{G C} \subseteq\left\{P_{G C}\right\}$ and hour $h ; I_{a, n s, n i}{ }^{(h)}$ - the current of the non-switchable consumer $n_{i}$ connected on the phase $a$, at the pillar $p_{C G} \subseteq\left\{P_{G C}\right\}$, and hour $h ; I_{b, n s, n j}(h)$ - the current of the non-switchable consumer $n_{j}$ connected on the phase $b$, at the pillar $p_{C G} \subseteq\left\{P_{G C}\right\}$, and hour $h ; I_{c, n s, n l}(h)$ - the current of the non-switchable consumer $n l$ connected on the phase $c$, at the pillar $p_{C G} \subseteq\left\{P_{G C}\right\}$, and hour $h ; I_{a, s, m i}{ }^{(h)}$ - the current of the switchable consumer $m_{i}$ belonging the candidate groups GC connected on the phase $a$, at the pillar $p_{C G} \subseteq\left\{P_{G C}\right\}$, and hour $h ; I_{b, s, m j}(h)$ - the current of the switchable consumer $m_{j}$ belonging the candidate groups GC connected on the phase $b$, at the pillar $p_{C G} \subseteq\left\{P_{G C}\right\}$, and hour $h ; I_{c, s, m l}(h)$ - the current of the switchable consumer $m l$ belonging the candidate groups GC connected on the phase $c$, at the pillar $p_{C G} \subseteq\left\{P_{G C}\right\}$, and hour $h ; N_{a, n s, p G C^{(h)}, N_{b, n s, p G C}(h), N_{c, n s, p G C}(h)}$ - the number of the non-switchable consumers connected on the phases $a, b$, and $c$, at the pillar $p_{G C} \subseteq\left\{P_{G C}\right\}$, and hour $h ; N_{a, s, p G C}(h), N_{b, s, p G C}(h), N_{c, s, p G C}(h)$ - the number of the switchable consumers belonging the candidate groups GC connected on the phases $a, b$, and $c$, at the pillar $p_{G C} \subseteq\left\{P_{G C}\right\}$, and hour $h ; N_{C, n s, p \subset G}(h)$-the total number of the non-switchable consumers connected at the pillar $p_{G C} \subseteq\left\{P_{G C}\right\}$, and hour $h ; N_{C, s, p C G}(h)$ - the total number of the switchable consumers belonging the candidate groups GC connected at the pillar $p_{C G} \subseteq\left\{P_{G C}\right\}$, and hour $h$; $N_{C, p \subset G}{ }^{(h)}$ - the total number of the consumers connected at the pillar $p_{C G} \subseteq\left\{P_{G C}\right\}$, and hour $h$; $N_{a, n s}-$ the total number of the non-switchable consumers from the $\mu \mathrm{G}$ connected on the phase $a ; N_{b, n s}-$ the total number of the non-switchable consumers from the $\mu \mathrm{G}$ connected on the phase $b ; N_{c, n s}-$ the total number of the non-switchable consumers from the $\mu \mathrm{G}$ connected on the phase $c ; N_{a, s}(h)-$ the total number of the switchable consumers (belonging to the "candidate" groups) from the $\mu \mathrm{G}$ connected on the phase $a$, at hour $h ; N_{b, s}(h)$ - the total number of the switchable consumers (belonging to the "candidate" groups) from the $\mu \mathrm{G}$ connected on the phase $b$, at hour $h ; N_{c, s}(h)$ - the total number of the switchable consumers (belonging to the "candidate" groups) from the $\mu \mathrm{G}$ connected on the phase $c$, at hour $h ; n_{a}^{(h)}$ - the total number of the consumers from the $\mu \mathrm{G}$ connected on the phase $a$, at hour $h$; $n_{b}{ }^{(h)}$ - the total number of the consumers from the $\mu \mathrm{G}$ connected on the phase $b$, at hour $h_{;} n_{c}^{(h)}-$ the total number of the consumers from the $\mu \mathrm{G}$ connected on the phase $c$, at hour $h$; $H$-the analysed time period.

Fig. 6 presents the implementation procedure of the mathematical model (20)-(40). 


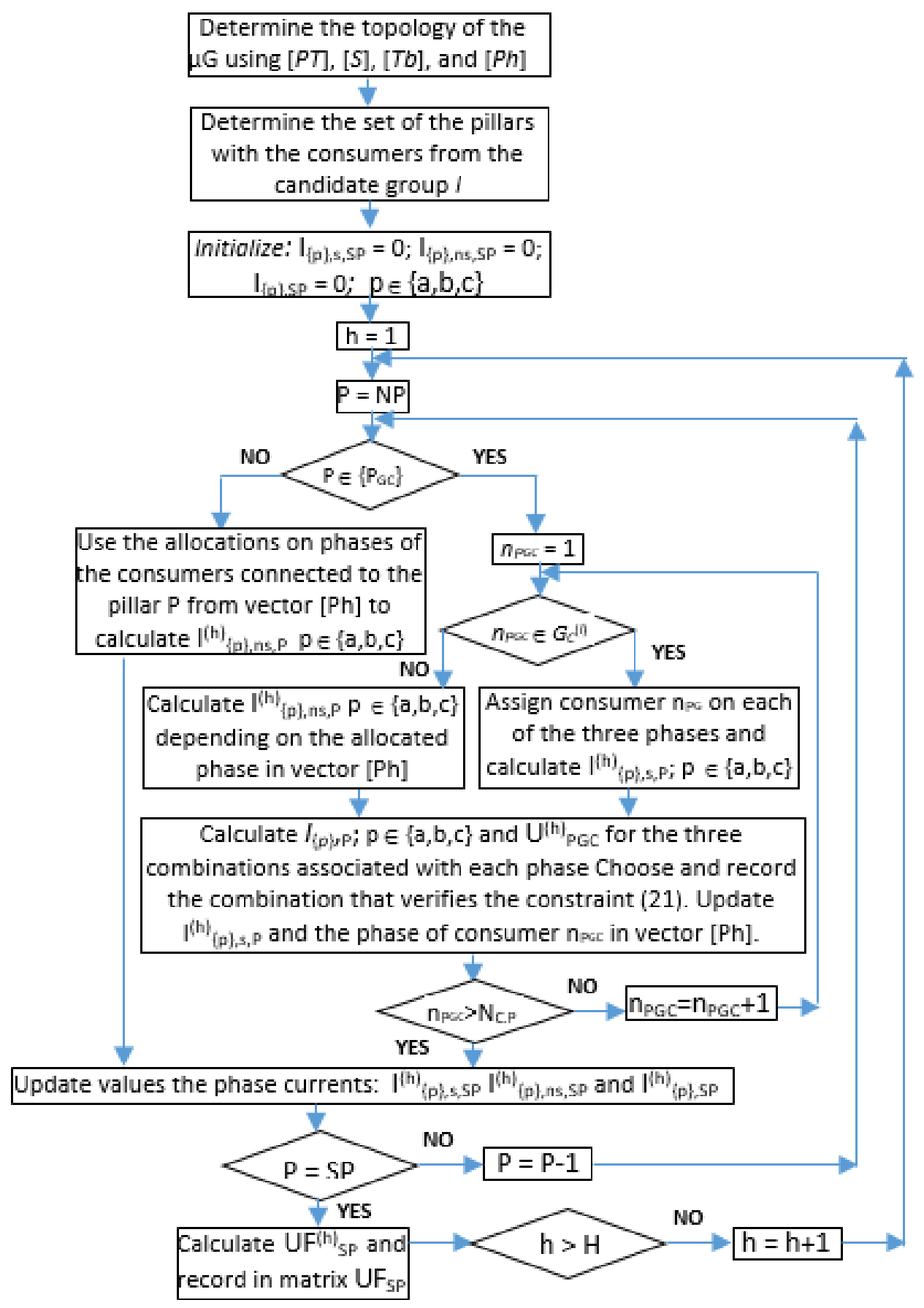

Fig. 6. The flow-chart of the phase load balancing process

For a better understanding, Fig. 7 exemplifies the implementation of the proposed PLB algorithm using the test $\mu \mathrm{G}$ presented in Section 3.1.1, where consumer C9 connected to the pillar P7 has a PLBE installed. The colour used to highlight the phase currents on each section is red and yellow for the modified values due to switching the consumer C9 from phase $a$ to $b$. Thus, the value of the $U F$ at the SP level has been reduced from 1.11 to 1.004. Also, the effect of this switching operation, quantified through a value of the UF below 1.1 (maximum value accepted by the DGO in the $\mu G s$ ), feels at the level of each pillar. 


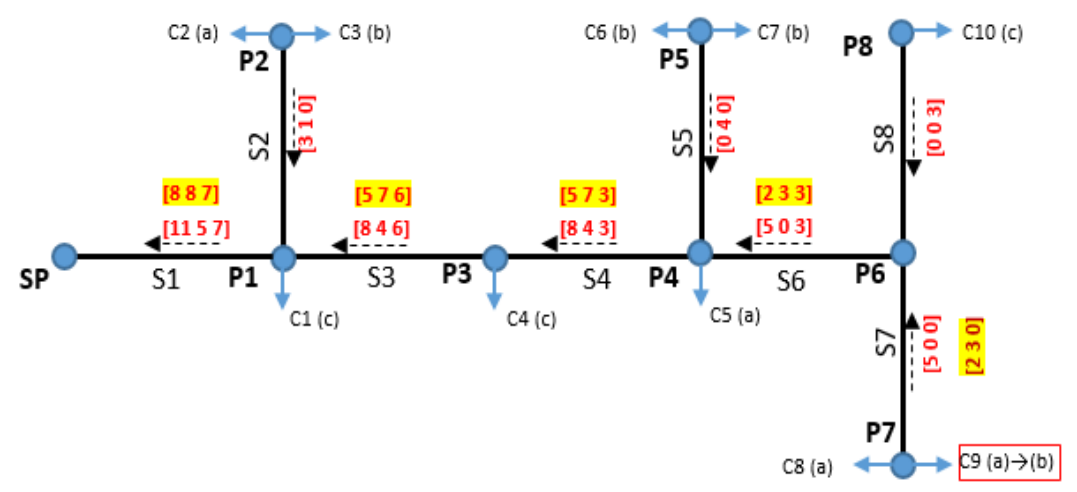

Fig. 7. The PLB procedure detailed for the $\mu \mathrm{G}$ from Fig. 4

The proposed methodology has the following advantages:

- It can be applied in the real $\mu \mathrm{Gs}$ with complex topologies and a high number of 1-P consumers.

- It uses in the first level a clustering-based selection criterion to obtain the "candidate" groups of the 1-P consumers which participate in the PLB process, with significant influence on the minimization of the unbalance factor.

- It integrates into the second level a PLB algorithm that aims minimization of the unbalance factor at the SP level, subject to the constraints regarding its value below an imposed limit at the pillars where the 1-P consumers from the "candidate" groups are connected. The fast computational time and convergence speed represent strengths compared with other algorithms.

\section{Case Study}

A real $\mu \mathrm{G}$, having the rated voltage by $0.4 \mathrm{kV}$, belonging to the DGO from the northeast of Romania was considered in the testing of the proposed methodology. Fig. 8 presents the topology of the analysed $\mu \mathrm{G}$ where the following colours were used to emphasize the type (1-P or 3-P) and allocation of the consumers on the phases: red (1-P consumer, phase $a$ ), blue (1-P consumer, phase $b$ ), yellow (1-P consumer, phase $c$ ), and magenta (3-P consumers). Table 3 presents details of the characteristics associated with the sections of the $\mu \mathrm{G}$. It can be observed that $62.5 \%(2.2 \mathrm{~km})$ from the total length has the cross-section of phase and neutral conductors by $50 \mathrm{~mm}^{2}$, this section being associated with the main trunk of the network. The lateral branches, having a total length of $1.32 \mathrm{~km}$ are both 1-P (18.2 \%) and 3-P (19.3\%), with the cross-sections of the conductors less than $35 \mathrm{~mm}^{2}$.

Fig. 9 presents the type (1-P or 3-P) and the initial allocation of the phases for all consumers. The analysis of the information highlights that most of the 1-P consumers are allocated on the phase $b(48.2 \%)$, followed by phase $c(36.8 \%)$, and phase $a(14 \%)$. Only one consumer $(0.9 \%)$ connected at the pillar P10 has 3-P branching. The vectors $[\mathrm{Tb}]$ and $[\mathrm{Ph}]$ will contain these data (see Table A1 from Annex A).

Table 3. The characteristics of the sections

\begin{tabular}{|c|c|c|c|c|}
\hline \multirow[b]{2}{*}{ No. } & \multicolumn{2}{|c|}{ Cross-section } & \multirow[b]{2}{*}{ Type } & \multirow{2}{*}{$\begin{array}{c}\text { Length } \\
{[\mathrm{km}]}\end{array}$} \\
\hline & $\begin{array}{c}\text { Phase } \\
\text { conductor }\end{array}$ & $\begin{array}{l}\text { Neutral } \\
\text { conductor }\end{array}$ & & \\
\hline 1 & $3 \times 50$ & 50 & Classical & 2.08 \\
\hline 2 & $3 \times 50$ & 50 & Stranded & 0.12 \\
\hline 3 & $3 \times 35$ & 35 & Classical & 0.68 \\
\hline 4 & $1 \times 35$ & 35 & Classical & 0.28 \\
\hline 5 & $1 \times 25$ & 25 & Classical & 0.28 \\
\hline 6 & $1 \times 25$ & 16 & Classical & 0.08 \\
\hline \multicolumn{4}{|c|}{ Total } & 3.52 \\
\hline
\end{tabular}



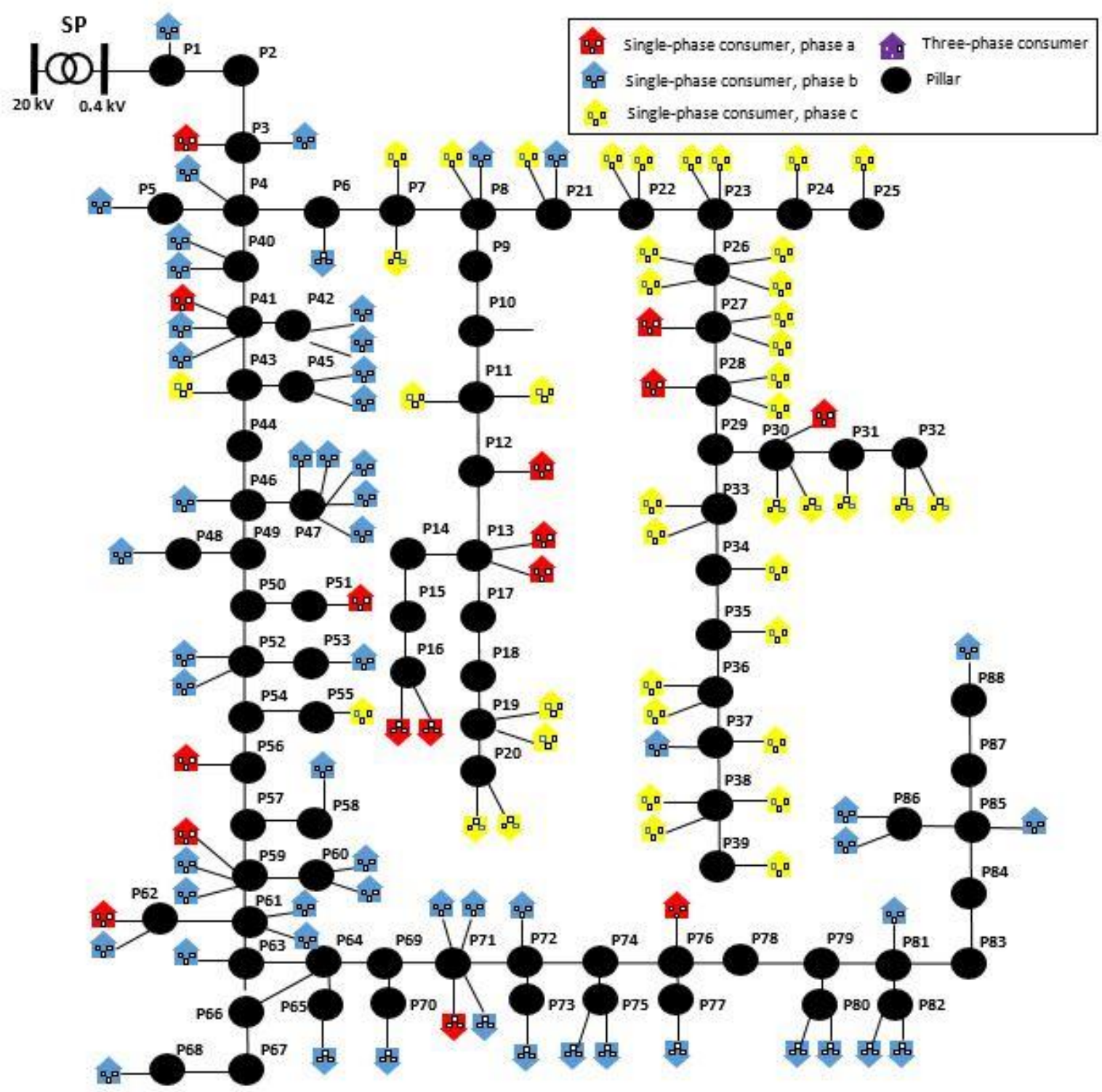

Fig. 8. The topology of the test $\mu \mathrm{G}$

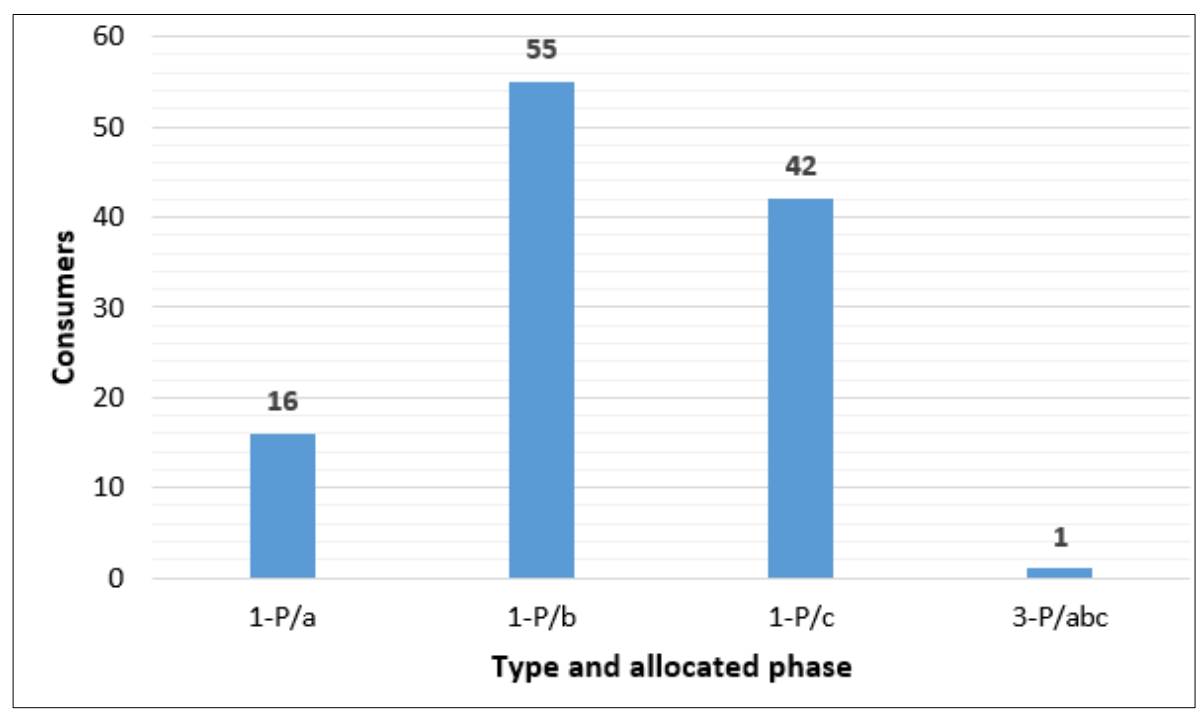

Fig. 9. The allocation of the consumers on the phases 
Another significant piece of information in testing the methodology refers to the consumers. In the analysed $\mu \mathrm{G}$, all consumers have the meters integrated into the SMS such that the current curves can be available, see the supplementary file. The information associated with the topology of the $\mu \mathrm{G}$ and current profiles is uploaded from the database of the DGO, representing the input data of the proposed methodology.

In the first stage, the matrix $[I D]$, having two columns associated with the vectors $\left[\operatorname{IhPL}_{\mathrm{h}}\right]$ and $[D]$ which contain the absorbed currents at the hour the peak load, $h_{P L}$, and the distances, $D_{n}, n=1, \ldots, N C$, from the SP to the pillar where each consumer is connected, is built. Then, based on the elements of the structure-vectors [VT1] and [VT2], all data related to the topology (pillars and sections) are recorded in the vectors $[P T]$ and $[S]$. Using these vectors and the additional information on the distance between two successive pillars $(0.04 \mathrm{~km})$ provided by the DGO according to the technical regulations in Romania [36], the calculation of the distances from the vector [D] is performed knowing the allocation of the consumers to the pillars. Finally, the current profiles of the consumers from the day with peak load recorded in the $\mu \mathrm{G}$ are uploaded in the matrix $[I]$.

To identify the hour of the peak load, $h_{P L}$, the aggregation process of the current profiles takes place at the LV level of the SP, see Fig. 10.

In the next step, the unbalance factor, UF, has been calculated at the peak load hour $\left(h_{P L}=22\right)$ to decide the initialization of the clustering process. Because the value of the UF was higher than 1.1 $(\mathrm{UF}=1.18)$, the column $\left[I_{22}\right]$ from the matrix $[I]$ together with the vector $[D]$ will compose the matrix [ID] used in the clustering process. The maximum number of the partitions $\left(K_{\max }=10\right)$ was determined using relation (14), knowing the number of consumers $\left(N_{C}=114\right)$. The optimal number of the clusters resulted in the clustering process was five. The testing of the quality has done using the silhouette coefficient, $S C$. The value of $S C$, equal to 0.76 , was maximum for a partition in five clusters, see Fig. 11.

Table 4 presents the statistical indicators (mean, standard deviation, maximum, and minimum) of each cluster (consumers' group) obtained in the clustering process based on the K-means algorithm. Most consumers (80\% of the total consumers used in the clustering process) belonging to the clusters (C1, C2, and C3) have small values of the absorbed currents at the hour. This situation is usually in the rural distribution networks from Romania because the electricity consumption of many consumers is under $1000 \mathrm{~kW} /$ year. On the other hand, the allocation of these consumers at the pillars indicates distances from the SP between 0.2 and $1.2 \mathrm{~km}$.

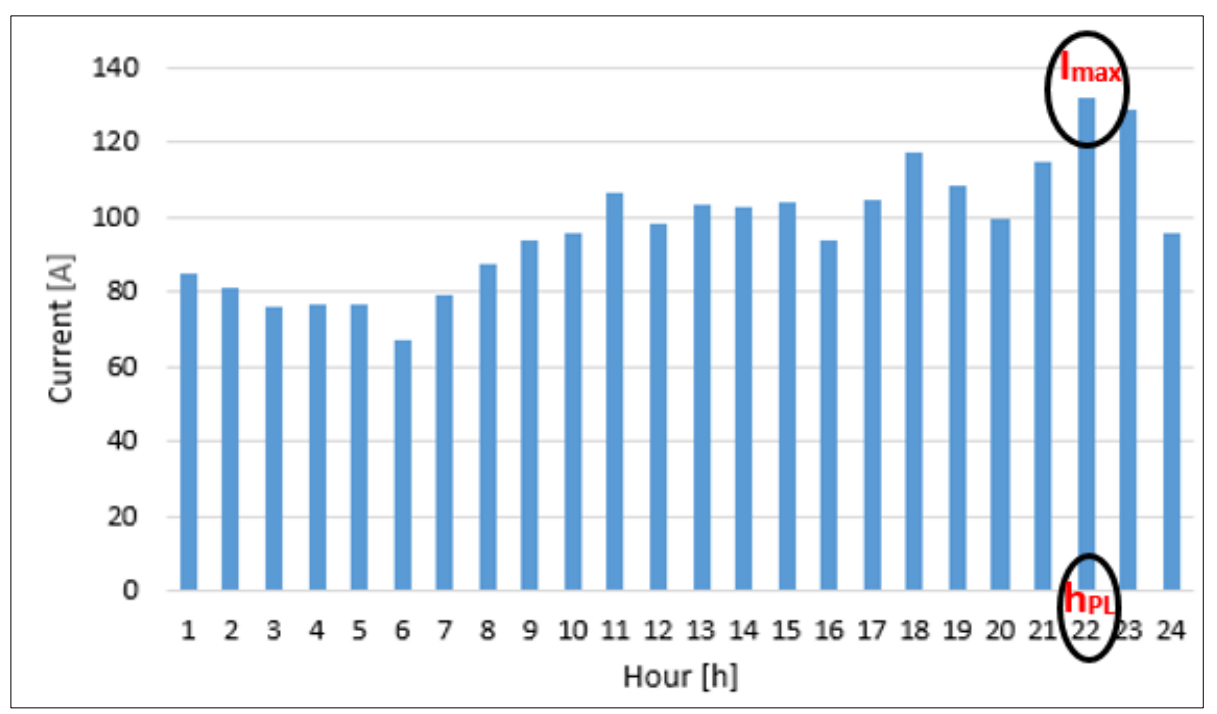

Fig. 10. The total current at the LV level of the SP 


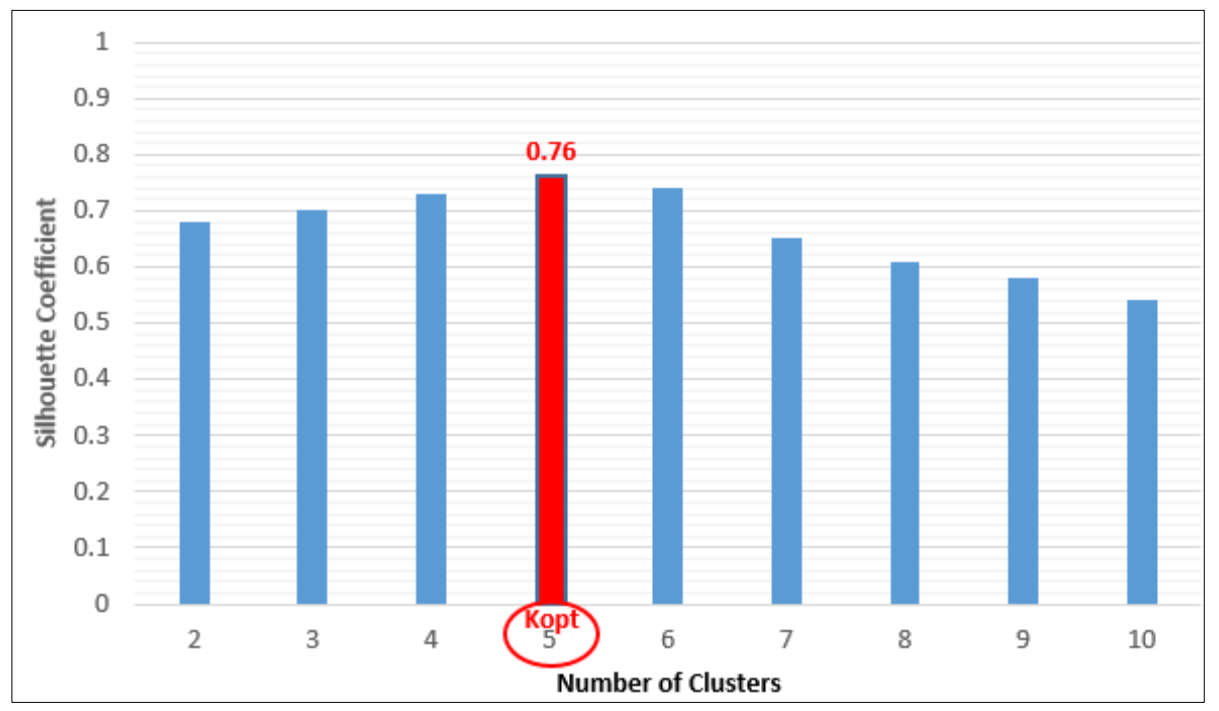

Fig. 11. The values of the silhouette coefficient for the maximum number of the partitions $\left(K_{\max }=10\right)$ with highlighting the optimal partition $\left(K_{\text {opt }}=5\right)$

Table 4. The statistical indicators of the clusters

\begin{tabular}{|c|c|c|c|c|c|c|}
\hline \multirow{2}{*}{$\begin{array}{l}\text { Statistical } \\
\text { indicators }\end{array}$} & \multirow{2}{*}{ Variables } & \multicolumn{5}{|c|}{ Cluster } \\
\hline & & $\mathrm{C} 1$ & $\mathrm{C} 2$ & $\mathrm{C} 3$ & $\mathrm{C} 4$ & C5 \\
\hline \multirow{2}{*}{ Mean } & $\mathrm{D}[\mathrm{km}]$ & 0.56 & 0.29 & 0.39 & 0.96 & 0.60 \\
\hline & I [A] & 0.48 & 0.63 & 8.25 & 0.69 & 1.60 \\
\hline \multirow{2}{*}{$\begin{array}{l}\text { Standard } \\
\text { deviation }\end{array}$} & $\mathrm{D}[\mathrm{km}]$ & 0.09 & 0.10 & 0.19 & 0.15 & 0.11 \\
\hline & I [A] & 0.19 & 0.43 & 2.33 & 0.53 & 0.65 \\
\hline \multirow{2}{*}{$\begin{array}{l}\text { Maximum } \\
\text { value }\end{array}$} & $\mathrm{D}[\mathrm{km}]$ & 0.72 & 0.40 & 0.64 & 1.28 & 0.76 \\
\hline & I [A] & 1.01 & 2.33 & 11.70 & 2.33 & 3.10 \\
\hline \multirow{2}{*}{$\begin{array}{l}\text { Minimum } \\
\text { value }\end{array}$} & $\mathrm{D}[\mathrm{km}]$ & 0.44 & 0.04 & 0.20 & 0.76 & 0.40 \\
\hline & I [A] & 0.34 & 0.21 & 6.66 & 0.34 & 1.01 \\
\hline \multicolumn{2}{|c|}{ Number } & 32 & 34 & 4 & 26 & 18 \\
\hline
\end{tabular}

Cluster $\mathrm{C} 5$ contains consumers with have values in the range [1.5 A, 4.5 A ], and C3, having the smallest number of consumers, is characterized by values of the currents over $6 \mathrm{~A}$. Most consumers from Cluster $\mathrm{C} 5$ are connected to the pillars located in the middle zone of the network, the distances from the SP being between 0.5 and $0.76 \mathrm{~km}$.

In the next stage, the "candidate" groups have been chosen based on the qualification index, QI. Table 5 contains the information on the qualification index and the degrees of importance assigned to the proposed zones. A qualification index from 9 (the highest importance) until 1 (the least importance) will label each zone classified in Table 5. The zoning process was based on the analysis of the results obtained in the clustering process and presented above. Fig. 12 shows the 3-D representation of the clusters considering the absorbed current, distance, and qualification index.

Table 5. The value of the qualification index and the degrees of importance associated with zoning of the characteristics current - distance

\begin{tabular}{|c|c|c|c|c|}
\hline \multirow{2}{*}{$\begin{array}{c}\text { Zones of } \\
\text { the current }\end{array}$} & \multicolumn{3}{|c|}{ Zones of the distance [km] } & \multirow{2}{*}{$\begin{array}{c}\text { Qualification } \\
\text { index }\end{array}$} \\
\hline & $0-0.4 \mathrm{~km}$ & $0.4-0.8 \mathrm{~km}$ & $0.8-1.2 \mathrm{~km}$ & \\
\hline $0-1.5 \mathrm{~A}$ & 1 & 2 & 3 & Low \\
\hline $1.5-4.5 \mathrm{~A}$ & 4 & 5 & 6 & Medium \\
\hline$>4.5 \mathrm{~A}$ & 7 & 8 & 9 & High \\
\hline
\end{tabular}




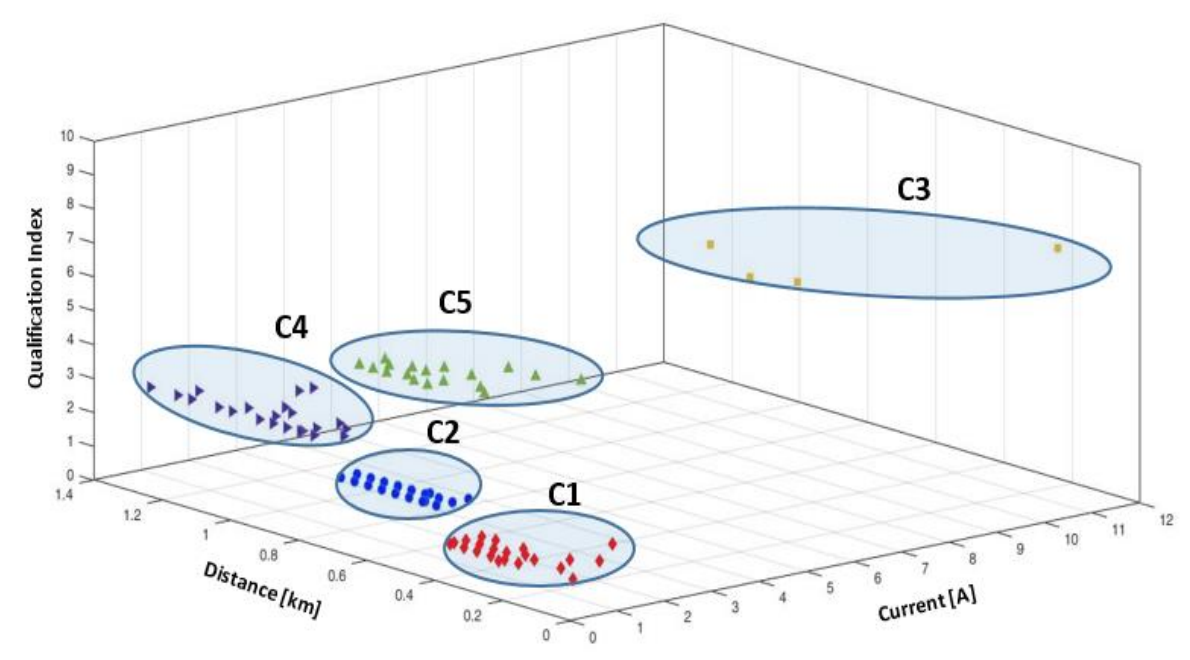

Fig. 12. The representation of the clusters depending on the qualification index

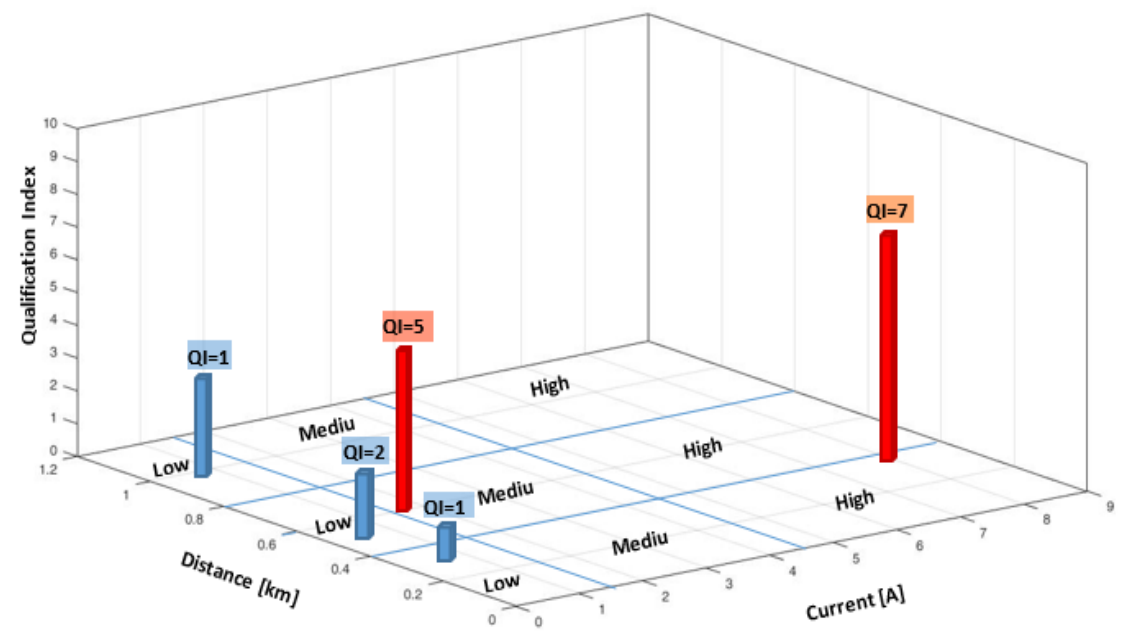

Fig. 13. The representation of the centroids with the value of the qualification index associated with each cluster

The centroids, represented by the mean presented in Table 4, will characterize each cluster in the identification process of the "candidate" groups. The interest zones for the PLB process will have the values of QI, in descending order, between 9 and 4, associated with the High and Medium degrees of importance, see Fig. 13. The clusters from these zones, highlighted in red, are Cluster C3 (High degree, $Q I=7$ ) and Cluster C5 (Medium degree, $Q I=5$ ). These clusters represents the "candidate" groups for the PLB process in this case, where each consumer will have installed a PLBE.

The second level of the methodology refers to running the PLB algorithm considering the "candidate" groups in descending order of the QI (C3 and C5) until the convergence condition is satisfied. The value imposed to stop the iterative process was 1.01, meaning an acceptance of $1 \%$ for the unbalance factor at the SP level, and the imposed limit of the unbalance factor at the pillar level, UF lim, see constraint (21), was 1.1 (maximum value accepted by the DGO in the $\mu \mathrm{Gs}$ ).

The algorithm starts from the farthest points (P20, P39, and P88), aggregating the phase currents at each pillar until the SP. The optimal solution, represented by the minimum average value of the UF at the level of the SP in the analysed period, is obtained through coordination of the PLBE installed to the consumers from the "candidate" groups. Thus, the best allocation of the consumers on the phases of the $\mu \mathrm{G}$ is determined. Fig. 14 shows the hourly values of the UF at the LV level of the SP obtained after applying the PLB algorithm. The analysis of data indicates a maximum value of 1.0078 recorded at the hour of the peak load $\left(h_{P L}=22\right)$ and an average of 1.003. This last value is well below the target value of 1.01 , set to stop the iterative process. 


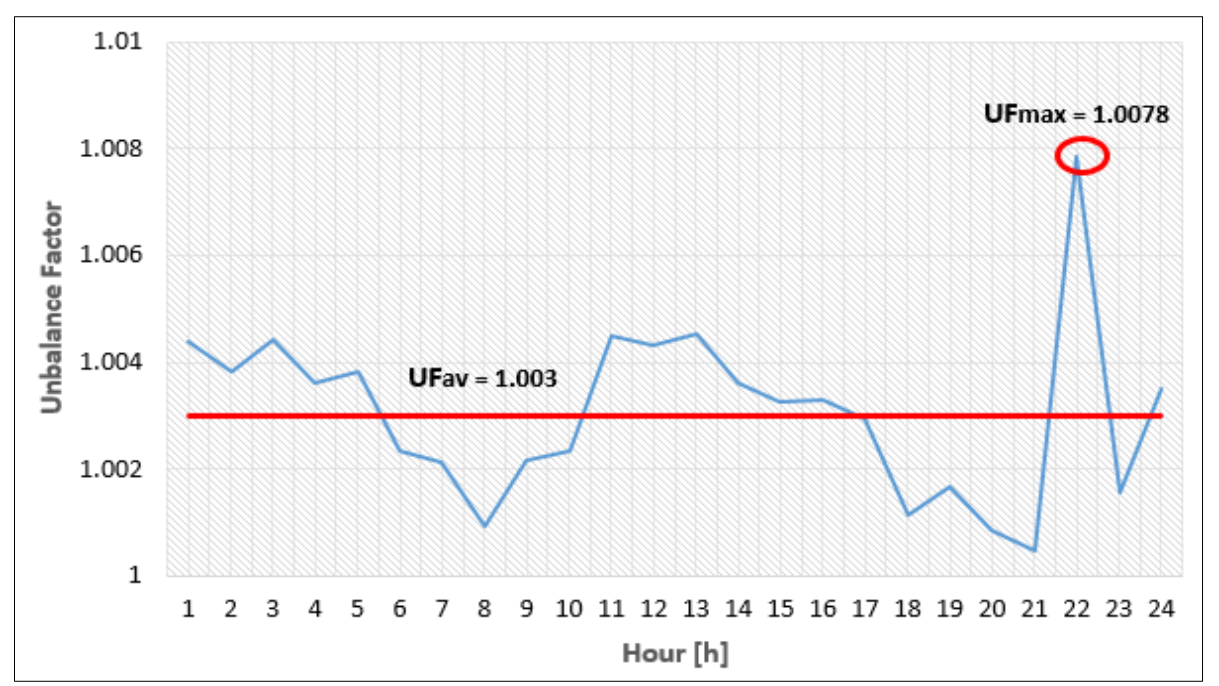

Fig. 14. The hourly values of the unbalance factor obtained with the proposed algorithm

The results have been compared with the full implementation degree (FID)-based algorithm proposed in [39], where all consumers have the PLBE installed (100\% implementation degree) because the computational time (1.26 seconds) was over others PLB algorithms based on the PSO [41] (348 seconds) and GA [42] (291 seconds). The code of the algorithm has been written in Matlab2016 and running on a computer Intel Core i7, 3.10 GHz, 4GB RAM, and WIN 10 64-bit operating system. Fig. 15 presents the results obtained with both algorithms, FID algorithm [39], where there is a full implementation degree $(100 \%)$ of the PLBE, and the proposed algorithm, with clustering-based consumers' selection criterion for placement of the PLBE, where the implementation degree is $17.5 \%$.

Fig. 16 presents the switching diagrams of the PLBE installed to the consumers from the "candidate" groups and Table A2 from Annex A contains details on the PLB process highlighted through the switching matrix.

The analysis of the diagrams and matrix associated with the switching operations concluded that the first eleven consumers, located closer to the SP, have a higher number of the switching operations (98, representing $81.7 \%$ of the total number) than the last eleven consumers (22, representing $18.3 \%$ from the total number), located close to the end pillars of the network. The switching of the consumers from one phase to another is different.

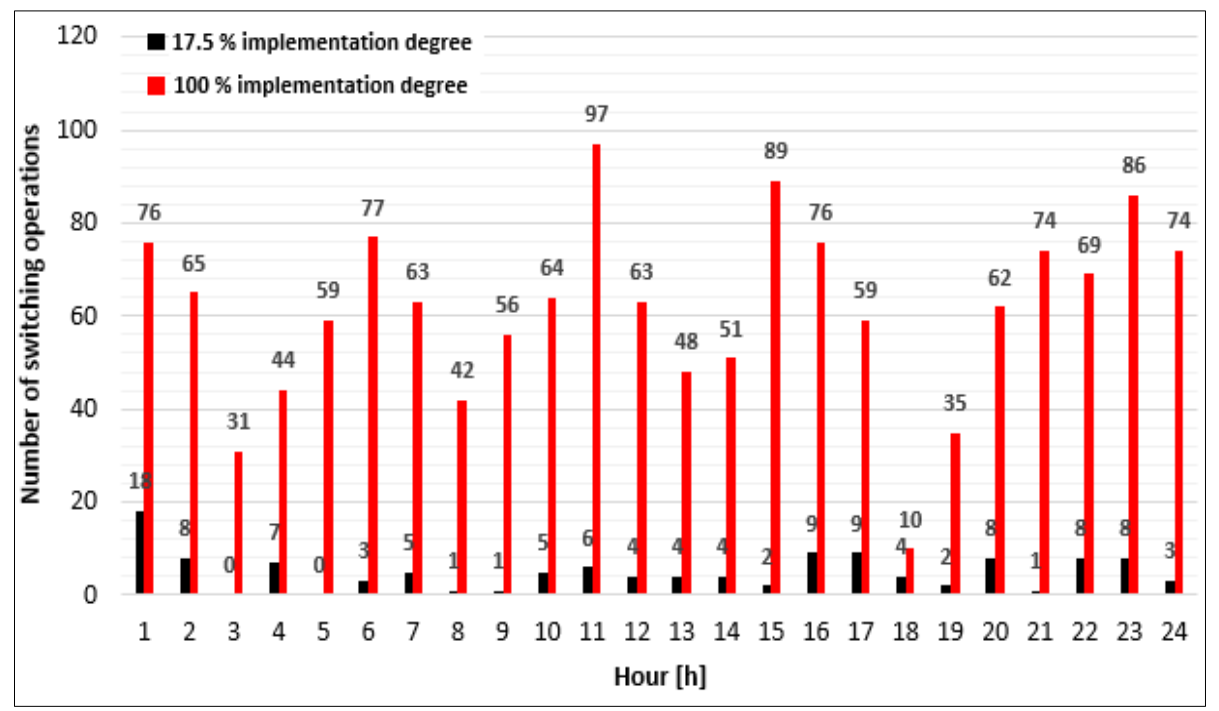

Fig. 15. Comparison between the two algorithms with $100 \%$ and $17.5 \%$ implementation degrees, considering the number of the switching operations 


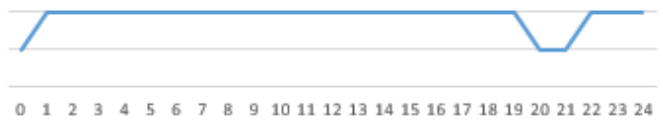

Consumer \#14
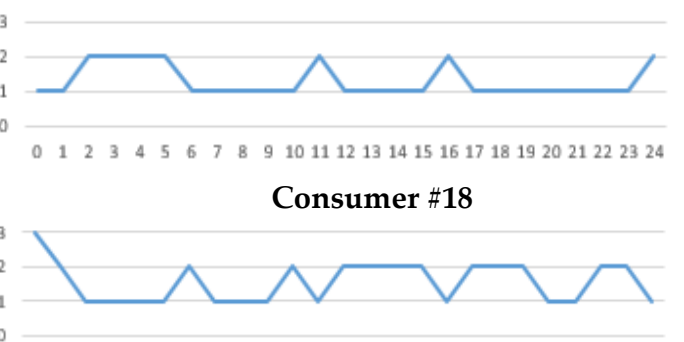

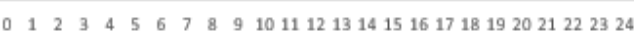

Consumer \#20

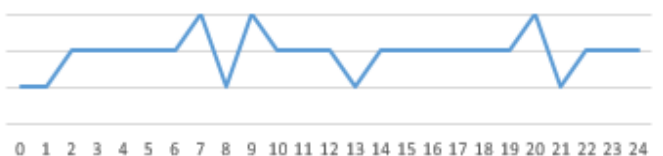

Consumer \#37

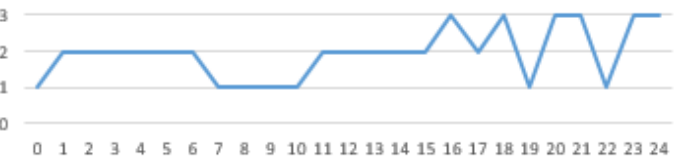

Consumer \#42

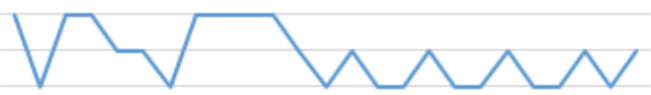

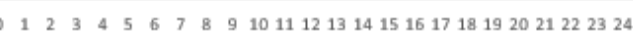

Consumer \#43

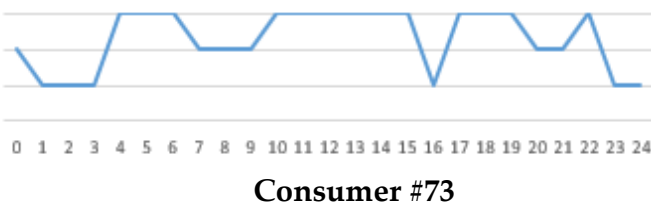

Consumer \#73

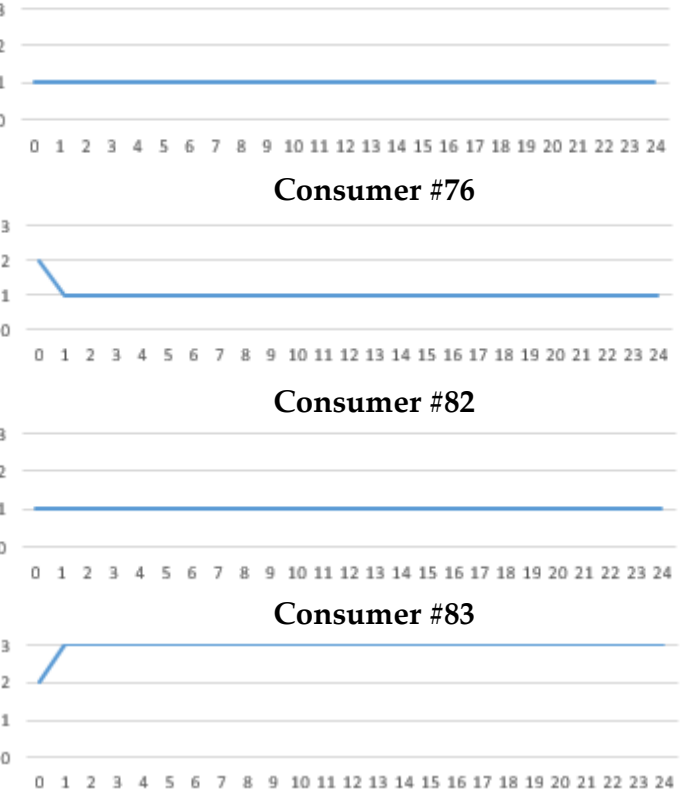

Consumer \#84

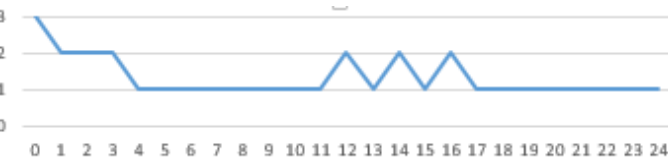

Consumer \#48

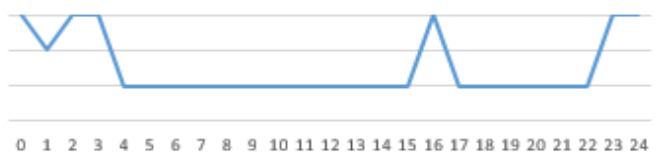

Consumer $\# 53$

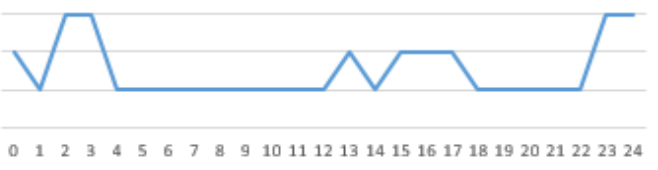

Consumer $\# \mathbf{5 4}$

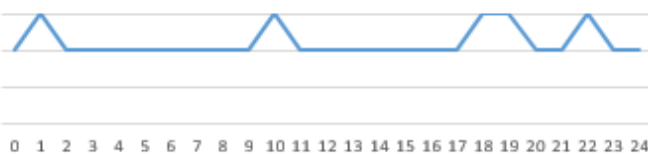

Consumer \#59

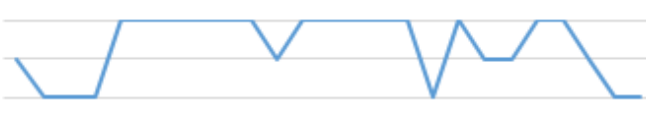

$\begin{array}{lllllllllll}0 & 1 & 2 & 3 & 4 & 5 & 6 & 7 & 8 & 9 & 1011 \\ 12 & 131415161718192021222324\end{array}$

Consumer \#68

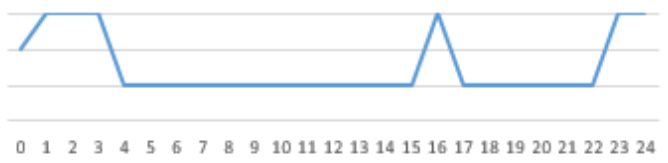

Consumer \#74

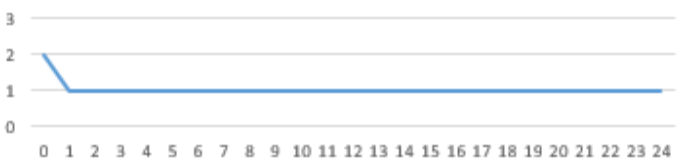

Consumer $\# 85$

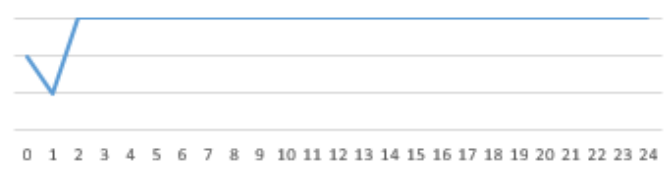

Consumer \#89

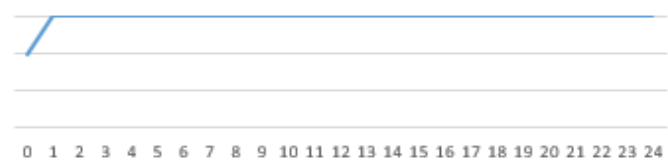

Consumer \#88

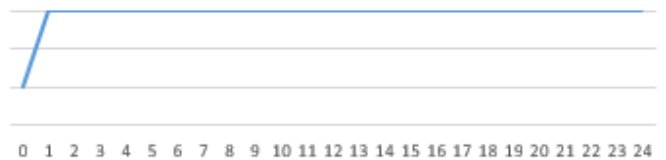

Consumer \#90

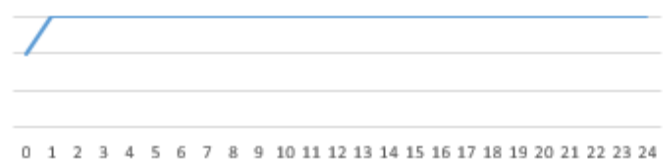

Consumer \#92

Fig. 16. The switching diagrams of the PLBE installed to consumers from the "candidate" groups. 
The hours with a high number of switching operations are 1 (18 operations), 16 and 17 (9 operations), 2, 20, 22, and 23 (8 operations). But, there are two hours ( 3 and 5) where the PLBE did not work. The PLBE from two consumers (76 and 83) did not perform the switching operations in the analysed interval, such that they were excluded from the set of "candidate" consumers. In these conditions, it can assert that 20 PLBE optimally located in the network lead at an unbalance factor by 1.003 , very close to the ideal value (1.0). The implementation degree of the PLBE in this $\mu G$ is only $17.5 \%$ (20 devices from a total number of 114 ).

All switching operations lead at a balanced loading on the three phases at each hour from the analysed period on the LV level of the SP, compared with the initial situation (unbalance regime, $0 \%$ implementation degrees of the PLBE), see Figs. 17 and 18. Table A3 from Annex A details the information on the phase currents and unbalance factors in all analysed cases $(0 \%, 17.5 \%$, and $100 \%$ implementation degrees).

Table 6 presents the synthesis with the performance indicators (the computing time, the unbalance factor, the total number of the switching operations in the analysed interval, and the energy-saving) for the three implemented degrees $(0 \%, 100 \%$, and $17.5 \%)$.

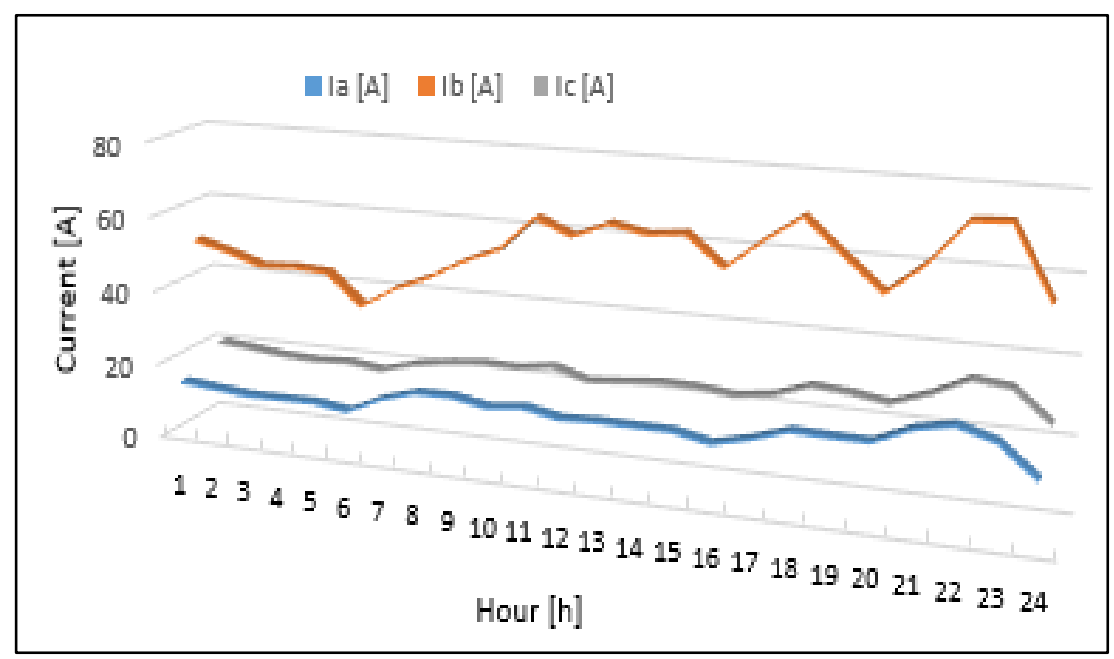

Fig. 17. The current curves on the three phases aggregated at the LV level of the SP, $(0 \%$ implementation degree of the PLBE in the $\mu \mathrm{G}$ )

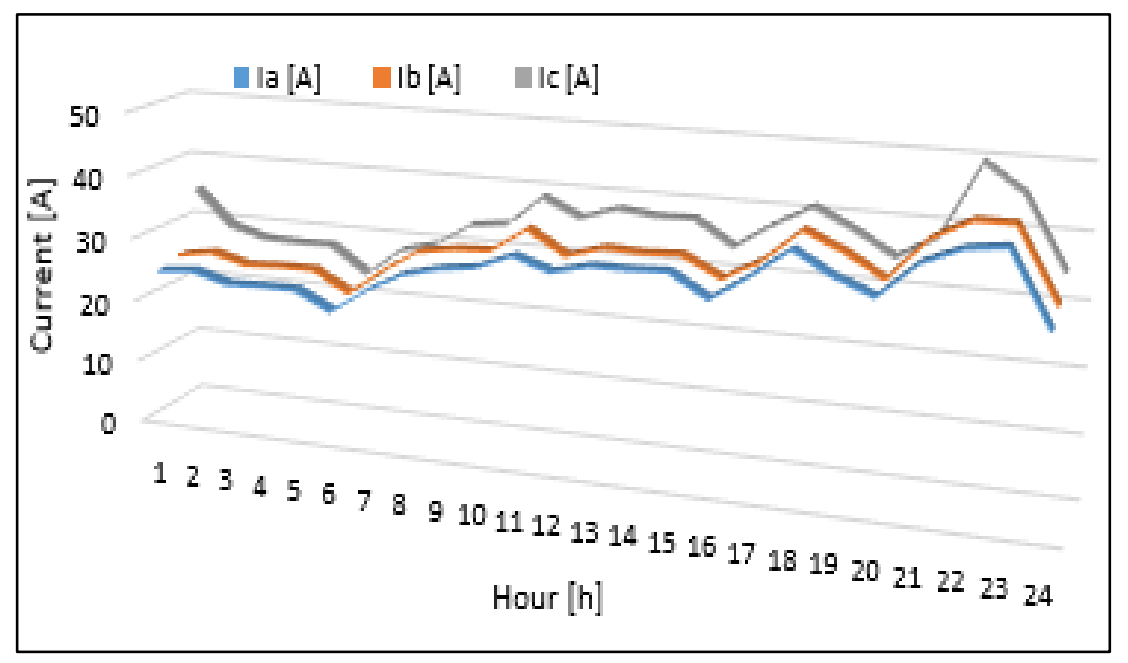

Fig. 18. The current curves on the three phases aggregated at the LV level of the SP (17.5\% implementation degree of the PLBE in the $\mu \mathrm{G}$ ) 
Table 6. The performance indicators obtained for both PLB algorithms

\begin{tabular}{cccccc}
\hline $\begin{array}{c}\text { Implementation degree } \\
{[\%]}\end{array}$ & $\begin{array}{c}\text { Computational } \\
\text { Time [seconds] }\end{array}$ & UF & $\begin{array}{c}\text { Switching } \\
\text { operations }\end{array}$ & $\begin{array}{c}\Delta \mathbf{W} \\
{[\mathbf{k W h}]}\end{array}$ & $\begin{array}{c}\Delta \mathbf{W} \mathrm{s} \\
{[\%]}\end{array}$ \\
\hline 0 & - & 1.260 & 0 & 35.81 & - \\
100 [FID Algorithm] & 1.26 & 1.0001 & 1470 & 14.10 & 60.6 \\
17.5 [Proposed algorithm] & 0.72 & 1.003 & 120 & 14.65 & 59.1 \\
\hline
\end{tabular}

The energy losses have been determined following the steady-state calculation at each hour using the forward/backward sweep-based algorithm developed in [35] for the balanced and unbalanced three-phase regimes of the $\mu$ Gs. Tables A4, A5, and A6, Annex A, show the detailed results of the steady-state calculation at each hour in the three cases. Fig. 19 shows the energy losses on the phases $(a, b$, and $c)$ and neutral $(\mathrm{N})$ conductors. The analysis highlights a significant reduction of the energy losses on phase $b$ and neutral for both implementation degrees. Also, the values of the energy losses in the conductors are very close, between $0.1 \mathrm{kWh}$ (phase $a$ ), $0.5 \mathrm{kWh}$ (phase $b$ ), $0.7 \mathrm{kWh}$ (phase $c$ ), and $0.3 \mathrm{kWh}$ (neutral). Finally, the following relation was used in the evaluation of the energy- saving $\left(\Delta W_{S}\right)$ :

$$
\Delta W_{s}=\left|\frac{\Delta W_{0}-\Delta W_{p g}}{\Delta W_{0}}\right| \cdot 100, \quad[\%]
$$

where: $\Delta W_{0}$ represents the energy losses in the unbalance case $(0 \%$ implementation degree of the PLBE in the $\mu \mathrm{G})$, and $\Delta W_{p g}$ corresponds the energy losses in the balanced cases ( $p g=100 \%$ and $17.5 \%$ ).

The analysis of the results from Table 6 highlights the efficiency of the proposed algorithm. If the values of the unbalance factor and energy-saving are very close, with small differences $(0.3 \%$ and $1.5 \%$, respectively), the computational time and the number of switching operations represent the strengths of the proposed algorithm. It is 0.54 seconds faster, and the switching operations are reduced by $92 \%$.

These last specific indicators will have a positive influence on the initial investments, due to the significant reduction of the PLBE and 3-P branching, obtaining similar technical benefits represented by the energy-saving as in the case when the implementation degree of the PLBE is full (100\%).

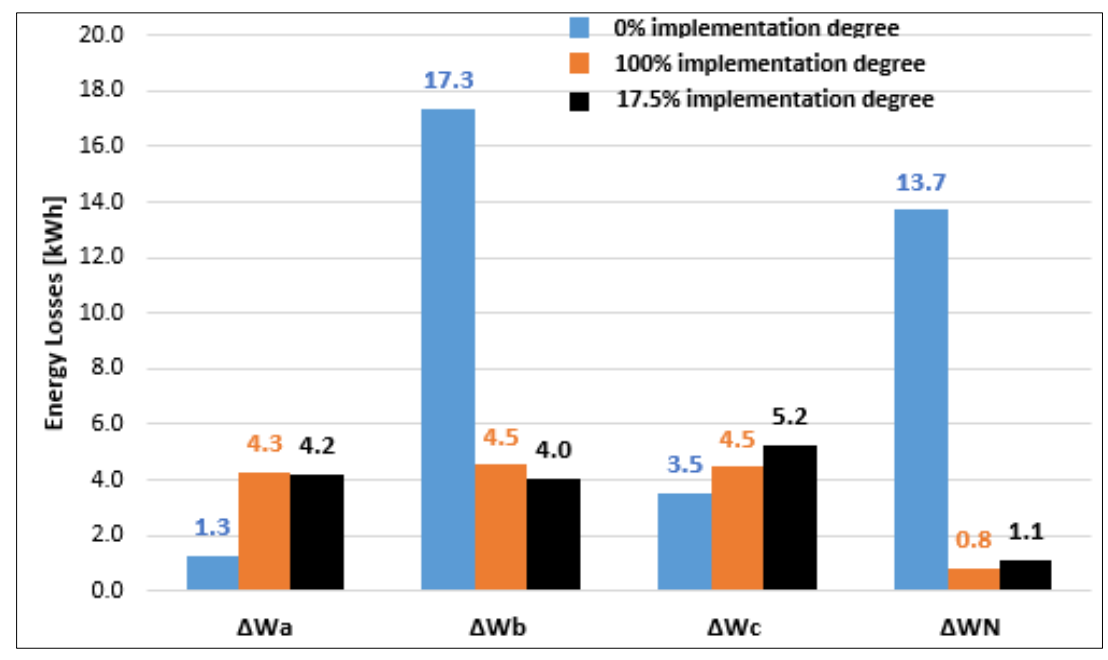

Fig. 19. The comparison between the energy losses in the phase and neutral conductors $(0 \%, 100 \%$, and $17.5 \%$ implemented degree of the PLBEs in the $\mu \mathrm{G}$ )

\section{Conclusions}

In the paper, a clustering-based bi-level methodology was proposed to determine the optimal placement of the PLBE to the consumers. The first level refers to a decision-making process where 
the "candidate" groups of the consumers with the PLBE installed are identified based on the K-means clustering algorithm and a qualification index. The second level integrates the PLB process described by the minimization of the unbalance factor on the LV side of the SP by switching from a phase to other phases the switchable consumers from the candidate groups. The energy-saving has represented the base in the evaluation of the technical benefits.

A real $\mu \mathrm{G}$ from a rural area belonging to a Romanian DGO, with 114 consumers, was considered in testing the proposed methodology. All consumers have the meter integrated into the SMS. Following the clustering process, two "candidate" groups having together 22 consumers were identified, based on the qualification index. Only 20 consumers participated in the PLB process because two consumers did not modify the connected phase in the analysed interval ( 24 hours). The analysis of the obtained results highlighted the efficiency of the proposed methodology compared with the approach where all consumers have the PLBE installed, meaning a full implementation degree $(100 \%)$. Thus, 20 PLBE installed to the consumers, representing an implementation degree by only $17.5 \%$, led to similar technical benefits as in the case of a full implementation degree $(100 \%)$ highlighted through the unbalance factor (1.003 versus 1.0001$)$ and an energy-saving $(59.1 \%$ versus $60.6 \%$ ), considering the number of switching operations decreases highly with the $92 \%$ (120 versus 1470). The computing time is 0.54 seconds faster than in the case of full implementation degree $(100 \%)$, mainly due to the reduced number of the PLBE and the local optimal solutions identified only at the level of the pillars where the consumers from the "candidate" groups are connected.

On the other hand, the methodology leads to significant economic benefits due to the reduced number of PLBE and 3-P branching. This branching must replace the 1-P branching at the consumers with PLBE installed.

But, the methodology can have a significant impact on the operation of the $\mu$ Gs only if the communication infrastructure has a high-speed data transmission, and the data concentrator located at the level of the SP, integrating the decision-making algorithm for the optimal switching of the consumers on the phases, has superior performances (high data acquisition and processing speed).

The future work of the authors is concentrated now on the $\mu$ Gs with prosumers to develop the solutions which integrate these small-scale distributed generation sources in the PLB process.

Supplementary Materials: The following are available online at http://www.mdpi.com/xxx/s1

Author Contributions: Conceptualization, G.G.; methodology, G.G. and L.N.; software, G.G.; validation, B.C.N., F.S., L.N., and E.C.; formal analysis, L.N. and E.C.; investigation, G.G., B.C.N., F.S., L.N., and E.C.; writingoriginal draft preparation, G.G., B.C.N., F.S., L.N., and E.C.; writing-review and editing, G.G. and B.C.N.; supervision, G.G. All authors discussed the results and have agreed with the structure of the paper. All authors have read and agreed to the published version of the manuscript.

Funding: This research received no external funding.

Conflicts of Interest: The authors declare no conflict of interest.

\begin{tabular}{|c|c|}
\hline \multicolumn{2}{|c|}{ Nomenclature } \\
\hline DGO & Distribution Grid Operator \\
\hline$\mu G$ & Microgrid \\
\hline SMS & Smart Metering System \\
\hline PLB & Phase load balancing \\
\hline $1-\mathrm{P}$ & Single-phase consumer \\
\hline 3-P & Three-phase consumer \\
\hline LV & Low voltage \\
\hline SP & Supply point \\
\hline MV & Medium voltage \\
\hline PEVs & Plug-in electric vehicles \\
\hline OF & Objective function \\
\hline C & Constraint \\
\hline
\end{tabular}




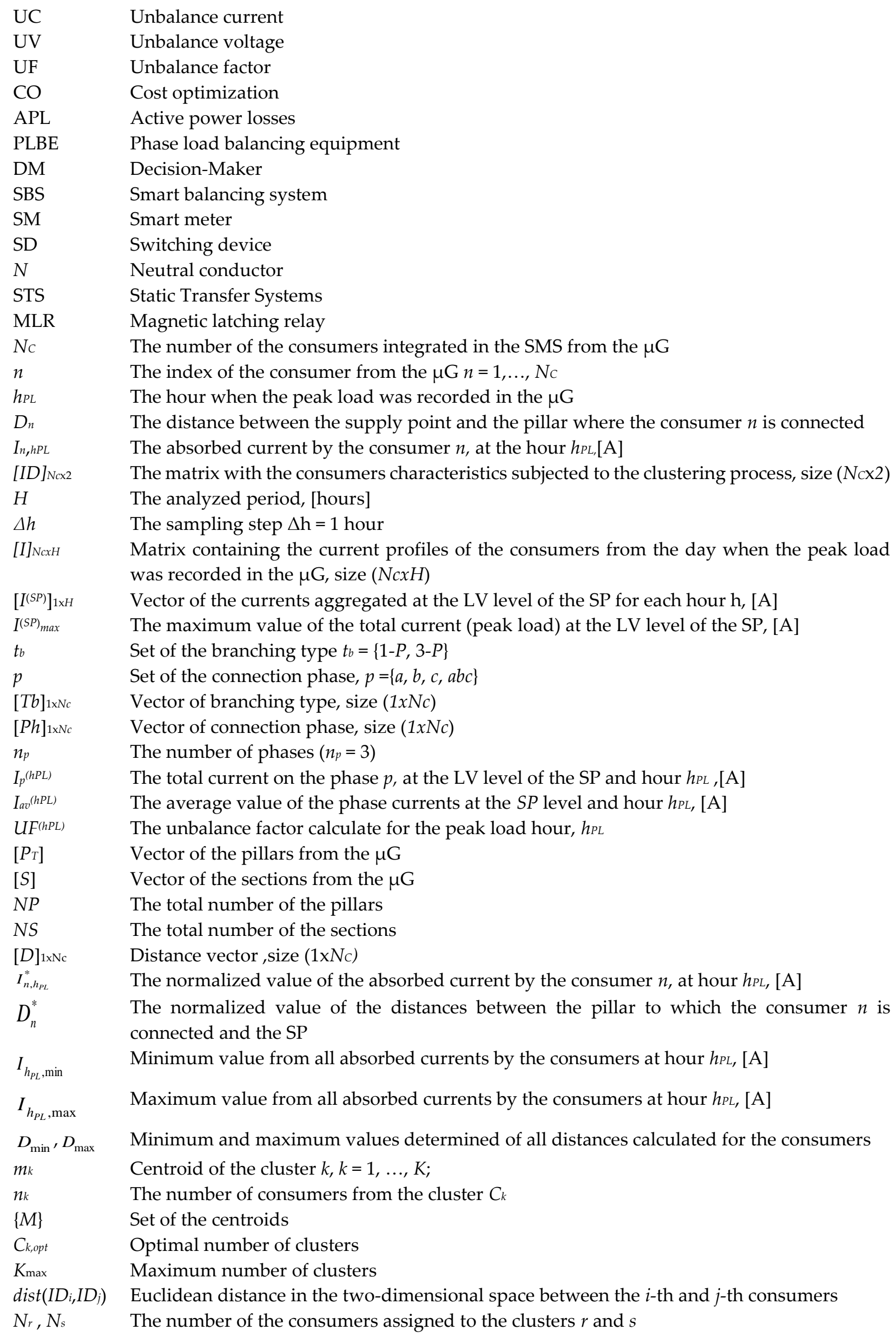


SC

$Q P$

QI

$U F_{a v, S P}$

Gc

$U F_{S P}{ }^{(h)}$

$\left\{P_{G C}\right\}$

$\left\{P_{T}\right\}$

$U F_{p G C^{(h)}}$

UF lim

$I_{a, S P}(h)$

$I b, S P(h)$

$I_{c, S P}(h)$

$I_{a v, S P}(h)$

$I_{a, n s, S P^{(h)}}$

$I b, n s, S P^{(h)}$

$I_{c, n s, S P}(h)$

$I_{a, s, S P}(h)$

$I_{b, s, S P}(h)$

$I_{c, s, S P}(h)$

$I_{a, n s, o}(h)$

$I b, n s, f^{(h)}$

$I_{c, n s, v}(h)$

$I_{a, s, q}(h)$

$I_{b, s, e}(h)$

$I_{c, s, w}(h)$

$I_{a, p G C^{(h)},}$

$I_{b, p G C}(h)$

$I_{c, p G C^{(h)}}$

$I_{a v, p \subset G^{(h)}}$

$I_{a, n s, p G C^{(h)}}$

$I b, n s, p \mathcal{C}^{(}(h)$

$I_{c, n s, p G C^{(h)}}$

$I_{a, s, p G C^{(h)}}$

$I_{b, s, p G C}(h)$

$I_{c, s, p G C^{(h)}}$

$I_{a, d}(h)$

Silhouette coefficient

Vector of the values of $S C Q P=\left[S C^{(2)}, S C^{(3)}, \ldots, S C^{(K \max )}\right]$.

Qualification indicator

The average value of the unbalance factor on the LV side of the SP

The number of "candidate" groups

The unbalance coefficient on the LV side of the SP and hour h;

Set of pillars with least one consumer from the "candidate" groups Gc is connected;

Set of all pillars from the analyzed $\mu \mathrm{G}$;

Unbalance coefficient for the hour $h$ at the pillar $p_{G C}$ where at least one consumer from the "candidate" groups Gc is connected;

Limit value accepted by the DGO for the unbalance coefficient in the $\mu \mathrm{Gs}$;

The current on the phase $a$ on the LV side of the SP and hour $h$, [A]

The current on the phase $b$ on the LV side of the SP and hour $h$, [A]

The current on the phase $c$ on the LV side of the SP and hour $h$, [A]

The average value of the phase currents on the LV side of the SP and hour $h$, [A]

The total current of the non-switchable consumers on the phase $a$ on the LV side of the SP and hour $h,[\mathrm{~A}]$

The total current of the non-switchable consumers on the phase $b$ on the LV side of the SP and hour $h,[\mathrm{~A}]$

The total current of the non-switchable consumers on the phase $c$ on the LV side of the SP and hour $h,[\mathrm{~A}]$

The total current of the switchable consumers on the phase $a$ on the LV side of the SP and hour $h,[\mathrm{~A}]$

The total current of the switchable consumers on the phase $b$ on the LV side of the SP and hour $h,[\mathrm{~A}]$

The total current of the switchable consumers on the phase $c$ on the LV side of the SP and hour $h,[\mathrm{~A}]$

The current of the non-switchable consumer $o$ connected on the phase $a$ and hour $h$, [A]

The current of the non-switchable consumer $f$ connected on the phase $b$ and hour $h$, [A]

The current of the non-switchable consumer $v$ connected on the phase $c$ and hour $h,[\mathrm{~A}]$

The current of the switchable consumer $q$ connected on the phase $a$ and hour $h$, [A]

The current of the switchable consumer $e$ connected on the phase $b$ and hour $h$, [A]

The current of the switchable consumer $w$ connected on the phase $c$ and hour $h,[\mathrm{~A}]$

The current on the phases $a$, at the pillar $p_{G C} \subseteq\left\{P_{G C}\right\}$, and hour $h,[\mathrm{~A}]$

The current on the phases $b$ at the pillar $p_{G C} \subseteq\left\{P_{G C}\right\}$, and hour $h,[\mathrm{~A}]$

The current on the phases $c$, at the pillar $p_{G C} \subseteq\left\{P_{G C}\right\}$, and hour $h,[A]$

The average value of the phase currents at the pillar $p_{C G} \subseteq\left\{P_{G C}\right\}$ and hour $h,[\mathrm{~A}]$

The current of the non-switchable consumers on the phase $a$, at the pillar $p_{G C} \subseteq\left\{P_{G C}\right\}$ and hour $h,[\mathrm{~A}]$

The current of the non-switchable consumers on the phase $b$, at the pillar $p_{G C} \subseteq\left\{P_{G C}\right\}$ and hour $h,[\mathrm{~A}]$

The current of the non-switchable consumers on the phase $c$, at the pillar $p_{G C} \subseteq\left\{P_{G C}\right\}$ and hour $h$, [A]

The current of the switchable consumers on the phase $a$, at the pillar $p_{G C} \subseteq\left\{P_{G C}\right\}$ and hour $h$, [A]

The current of the switchable consumers on the phase $b$, at the pillar $p_{G C} \subseteq\left\{P_{G C}\right\}$ and hour $h$, [A]

The current of the switchable consumers on the phase $c$, at the pillar $p_{G C} \subseteq\left\{P_{G C}\right\}$ and hour $h$, [A] $h,[\mathrm{~A}]$ 
$I_{b, d}(h) \quad$ The current on the phase $b$ at the pillar $d_{\subseteq}\left\{P_{T}\right\}$ (located downstream by pillar $p_{C G}$ ), and hour $h,[\mathrm{~A}]$

$I_{c, d}(h) \quad$ The current on the phase $c$ at the pillar $d_{\subseteq}\left\{P_{T}\right\}$ (located downstream by pillar $p_{C G}$ ), and hour $h,[\mathrm{~A}]$

$I_{a, n s, n i}(h) \quad$ The current of the non-switchable consumer $n_{i}$ connected on the phase $a$, at the pillar $p_{C G} \subseteq$ $\left\{P_{G C}\right\}$, and hour $h,[\mathrm{~A}]$

$I b, n s, n j j^{(h)} \quad$ The current of the non-switchable consumer $n_{j}$ connected on the phase $b$, at the pillar $p_{C G} \subseteq$ $\left\{P_{G C}\right\}$, and hour $h,[\mathrm{~A}]$

$I_{c, n s, n l}(h) \quad$ The current of the non-switchable consumer $n l$ connected on the phase $\mathrm{c}$, at the pillar $p_{C G} \subseteq$ $\left\{P_{G C}\right\}$, and hour $h,[\mathrm{~A}]$

$I_{a, s, m i}(h) \quad$ The current of the switchable consumer $m_{i}$ connected on the phase $a$, at the pillar $p_{C G} \subseteq\left\{P_{G C}\right\}$, and hour $h,[\mathrm{~A}]$

$I_{b, s, m j}(h) \quad$ The current of the switchable consumer $m_{j}$ connected on the phase $b$, at the pillar $p_{C G} \subseteq\left\{P_{G C}\right\}$, and hour $h,[\mathrm{~A}]$

$I_{c, s, m l}(h) \quad$ The current of the switchable consumer $m_{l}$ connected on the phase $c$, at the pillar $p_{C G} \subseteq\left\{P_{G C}\right\}$, and hour $h,[\mathrm{~A}]$

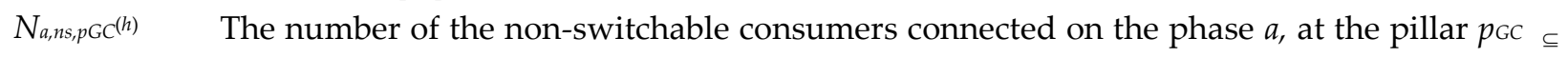
$\left\{P_{G C}\right\}$, and hour $h$

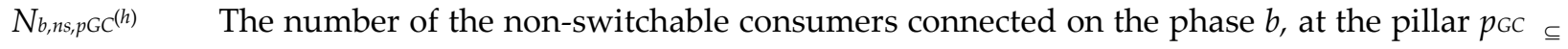
$\left\{P_{G C}\right\}$, and hour $h$

$N_{c, n s, p G C^{(h)}} \quad$ The number of the non-switchable consumers connected on the phase $c$, at the pillar $p_{G C} \subseteq$ $\left\{P_{G C}\right\}$, and hour $h$

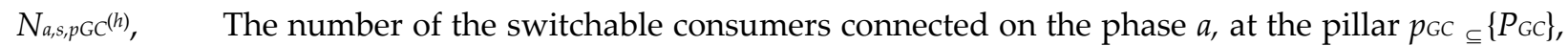
and hour $h$

$N_{b, s, p G C}(h) \quad$ The number of the switchable consumers connected on the phase $b$, at the pillar $p_{G C}\left\{P_{G C}\right\}$, and hour $h$

$N_{c, s, p G C}(h) \quad$ The number of the switchable consumers connected on the phase $c$, at the pillar $p_{G C}\left\{\left\{P_{G C}\right\}\right.$, and hour $h$

$N_{C, n s, p C G}(h) \quad$ The total number of the non-switchable consumers connected at the pillar $p_{G C}\left\{P_{G C}\right\}$, and hour $h$

$N_{C, s, p \subset G^{(h)}} \quad$ The total number of the switchable consumers connected at the pillar $p_{C G} \subseteq\left\{P_{G C}\right\}$, and hour $h$

$N_{C, p \subset G}(h) \quad$ Total number of the consumers connected at the pillar $p_{C G} \subseteq\left\{P_{G C}\right\}$, and hour $h$

$N_{a, n s}$

$N_{b, n s}$

$N_{c, n s}$

$N_{a, s}(h)$ the $\mu \mathrm{G}$ connected on the phase $a$, at hour $h$;

The total number of the non-switchable consumers from the $\mu \mathrm{G}$ connected on the phase $a$ The total number of the non-switchable consumers from the $\mu \mathrm{G}$ connected on the phase $b$ The total number of the non-switchable consumers from the $\mu \mathrm{G}$ connected on the phase $c$ The total number of the switchable consumers (belonging to the "candidate" groups) from

$N_{b, s}{ }^{(h)} \quad$ The total number of the switchable consumers (belonging to the "candidate" groups) from the $\mu \mathrm{G}$ connected on the phase $b$, at hour $h$;

$N_{c, s}(h) \quad$ The total number of the switchable consumers (belonging to the "candidate" groups) from the $\mu \mathrm{G}$ connected on the phase $c$, at hour $h$;

$n_{a}(h) \quad$ The total number of the consumers from the $\mu \mathrm{G}$ connected on the phase $a$, at hour $h$;

$n b^{(h)}$

$n_{c}^{(h)}$

FID

$\Delta W_{S}$

$\Delta W_{0}$ The total number of the consumers from the $\mu \mathrm{G}$ connected on the phase $b$, at hour $h$; The total number of the consumers from the $\mu \mathrm{G}$ connected on the phase $c$, at hour $h$; Full implementation degree-based algorithm

The energy-saving, [\%]

Energy losses in the unbalance case $(0 \%$ implementation degree of the PLBE installed in the $\mu \mathrm{G}),[\mathrm{kWh}]$

$\Delta W_{p g} \quad$ Energy losses in the balanced cases $(p g=100 \%$ and $17.5 \%),[\mathrm{kWh}]$ 


\section{Appendix A}

Table A1. The allocation of the consumers to the pillars and phases (initial situation)

\begin{tabular}{|c|c|c|c|c|c|c|c|c|}
\hline $\begin{array}{c}\text { Consumer } \\
\text { ID } \\
\end{array}$ & $\begin{array}{c}\text { Pillar } \\
\text { ID }\end{array}$ & $\begin{array}{c}\text { Initial Phase/ } \\
\text { Branching }\end{array}$ & $\begin{array}{c}\text { Consumer } \\
\text { ID } \\
\end{array}$ & $\begin{array}{c}\text { Pillar } \\
\text { ID }\end{array}$ & $\begin{array}{c}\text { Initial Phase/ } \\
\text { Branching } \\
\end{array}$ & $\begin{array}{c}\text { Consumer } \\
\text { ID } \\
\end{array}$ & $\begin{array}{c}\text { Pillar } \\
\text { ID }\end{array}$ & $\begin{array}{c}\text { Initial Phase/ } \\
\text { Branching }\end{array}$ \\
\hline 1 & 1 & $\mathrm{~b} / 1-\mathrm{P} / 1-\mathrm{P}$ & 39 & 28 & c/1-P & 77 & 52 & $\mathrm{~b} / 1-\mathrm{P}$ \\
\hline 2 & 3 & $\mathrm{a} / 1-\mathrm{P}$ & 40 & 28 & c / 1-P & 78 & 52 & $\mathrm{~b} / 1-\mathrm{P}$ \\
\hline 3 & 3 & $\mathrm{~b} / 1-\mathrm{P}$ & 41 & 30 & c / 1-P & 79 & 53 & $\mathrm{~b} / 1-\mathrm{P}$ \\
\hline 4 & 4 & b / 1-P & 42 & 30 & a / 1-P & 80 & 55 & c / 1-P \\
\hline 5 & 5 & b / 1-P & 43 & 30 & c / 1-P & 81 & 56 & a / 1-P \\
\hline 6 & 6 & b / 1-P & 44 & 31 & c / 1-P & 82 & 58 & b / 1-P \\
\hline 7 & 7 & c/1-P & 45 & 32 & c / 1-P & 83 & 59 & a / 1-P \\
\hline 8 & 7 & c / 1-P & 46 & 32 & c / 1-P & 84 & 59 & b / 1-P \\
\hline 9 & 8 & b / 1-P & 47 & 33 & c / 1-P & 85 & 59 & b / 1-P \\
\hline 10 & 8 & c / 1-P & 48 & 33 & c / 1-P & 86 & 60 & b / 1-P \\
\hline 11 & 10 & $\mathrm{a} b \mathrm{c} / 3-\mathrm{P}$ & 49 & 34 & c / 1-P & 87 & 60 & b / 1-P \\
\hline 12 & 11 & c / 1-P & 50 & 35 & c / 1-P & 88 & 61 & b / 1-P \\
\hline 13 & 11 & c / 1-P & 51 & 36 & c / 1-P & 89 & 61 & b / 1-P \\
\hline 14 & 12 & a / 1-P & 52 & 36 & c / 1-P & 90 & 62 & a / 1-P \\
\hline 15 & 13 & a / 1-P & 53 & 37 & c / 1-P & 91 & 62 & $\mathrm{~b} / 1-\mathrm{P}$ \\
\hline 16 & 13 & a / 1-P & 54 & 37 & b / 1-P & 92 & 63 & b / 1-P \\
\hline 17 & 16 & a / 1-P & 55 & 38 & c / 1-P & 93 & 65 & b / 1-P \\
\hline 18 & 16 & a / 1-P & 56 & 38 & c / 1-P & 94 & 68 & b / 1-P \\
\hline 19 & 19 & $c / 1-P$ & 57 & 38 & $c / 1-P$ & 95 & 70 & $\mathrm{~b} / 1-\mathrm{P}$ \\
\hline 20 & 19 & $c / 1-P$ & 58 & 39 & c / 1-P & 96 & 71 & a / 1-P \\
\hline 21 & 20 & c / 1-P & 59 & 40 & b / 1-P & 97 & 71 & b / 1-P \\
\hline 22 & 20 & c / 1-P & 60 & 40 & b / 1-P & 98 & 71 & $\mathrm{~b} / 1-\mathrm{P}$ \\
\hline 23 & 21 & b / 1-P & 61 & 41 & a / 1-P & 99 & 71 & b / 1-P \\
\hline 24 & 21 & c / 1-P & 62 & 41 & b / 1-P & 100 & 72 & b / 1-P \\
\hline 25 & 22 & c / 1-P & 63 & 41 & b / 1-P & 101 & 73 & b / 1-P \\
\hline 26 & 22 & c / 1-P & 64 & 42 & b / 1-P & 102 & 75 & b / 1-P \\
\hline 27 & 23 & c / 1-P & 65 & 42 & b / 1-P & 103 & 75 & b / 1-P \\
\hline 28 & 23 & c / 1-P & 66 & 43 & c / 1-P & 104 & 76 & a / 1-P \\
\hline 29 & 24 & c / 1-P & 67 & 45 & b / 1-P & 105 & 77 & b / 1-P \\
\hline 30 & 25 & c / 1-P & 68 & 45 & b / 1-P & 106 & 80 & b / 1-P \\
\hline 31 & 26 & c / 1-P & 69 & 46 & b / 1-P & 107 & 80 & b / 1-P \\
\hline 32 & 26 & c / 1-P & 70 & 47 & b / 1-P & 108 & 81 & b / 1-P \\
\hline 33 & 26 & $c / 1-P$ & 71 & 47 & b / 1-P & 109 & 82 & $\mathrm{~b} / 1-\mathrm{P}$ \\
\hline 34 & 26 & $\mathrm{c} / 1-\mathrm{P}$ & 72 & 47 & b / 1-P & 110 & 82 & b / 1-P \\
\hline 35 & 27 & c / 1-P & 73 & 47 & b / 1-P & 111 & 85 & b / 1-P \\
\hline 36 & 27 & c / 1-P & 74 & 47 & $\mathrm{~b} / 1-\mathrm{P}$ & 112 & 86 & $\mathrm{~b} / 1-\mathrm{P}$ \\
\hline 37 & 27 & a / 1-P & 75 & 48 & b / 1-P & 113 & 86 & b / 1-P \\
\hline 38 & 28 & a / 1-P & 76 & 51 & a / 1-P & 114 & 88 & b / 1-P \\
\hline
\end{tabular}


Table A2. The switching matrix and number of the switching operations

\begin{tabular}{|c|c|c|c|}
\hline \multicolumn{2}{|c|}{ Consumer Candidate } & Hour & \multirow{2}{*}{$\begin{array}{l}\text { Switching } \\
\text { Operations }\end{array}$} \\
\hline ID & group & $\begin{array}{lllllllllll}0 & 1 & 2 & 3 & 4 & 5 & 6 & 7 & 8 & 9 & 101112131415161718192021222324\end{array}$ & \\
\hline 14 & $\mathrm{C} 5$ & 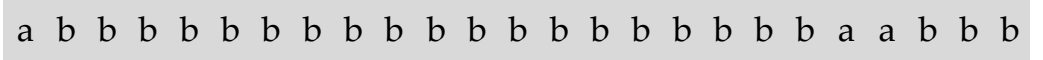 & 3 \\
\hline 18 & C5 & $a \mathrm{a} b \mathrm{~b} b \mathrm{~b}$ a a $a$ a $a b$ a $a$ a $a$ b a a $a$ a $a$ a $a b$ & 7 \\
\hline 20 & $\mathrm{C} 5$ & $c b a a a a b$ a $a$ a $b$ a b b b b a b b b a a b b a & 12 \\
\hline 37 & $\mathrm{C} 5$ & $a \quad a b b \quad b \quad b \quad b \quad c \quad a c b \quad b \quad b \quad a \quad b \quad b \quad b \quad b \quad b \quad b \quad c \quad a b b \quad b$ & 10 \\
\hline 42 & $\mathrm{C} 5$ & $a b b b \quad b \quad b \quad b \quad a \quad a \quad b \quad b \quad b \quad b \quad b \quad b \quad c a c c a c c$ & 10 \\
\hline 43 & $\mathrm{C} 5$ & $c a c c b b a c c c c b a b a a b a a b a a b a b$ & 16 \\
\hline 48 & $\mathrm{C} 5$ & $c b b$ a a a a a a a $a b a b$ a b a a a a a a $a$ & 8 \\
\hline 53 & $\mathrm{C} 5$ & c b c c a a a a a a a a a a a c a a a a a a c c & 6 \\
\hline 54 & $\mathrm{C} 5$ & $b$ a c c a a a a a a a a b a b b b a a a a a c c & 8 \\
\hline 59 & $\mathrm{C} 3$ & 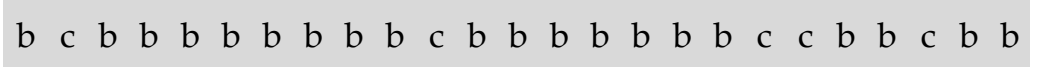 & 8 \\
\hline 68 & $\mathrm{C} 3$ & 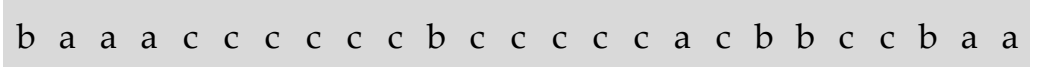 & 10 \\
\hline 73 & $\mathrm{C} 3$ & b c c c a a a a a a a a a a c a a a a a a c c & 5 \\
\hline 74 & C5 & 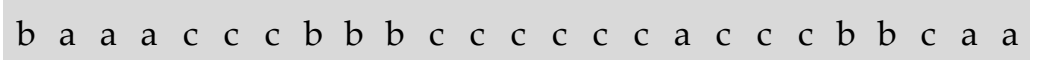 & 9 \\
\hline 76 & C5 & a a a a a a a a a a a a a a a a a a & 0 \\
\hline 82 & C5 & b a a a a a a a a a a a a a a a a a a & 1 \\
\hline 83 & $\mathrm{C} 5$ & a a a a a a a a a a a a a a a a a a & 0 \\
\hline 84 & $\mathrm{C} 3$ & 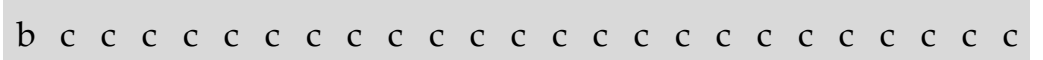 & 1 \\
\hline 85 & $\mathrm{C} 5$ & b a a a a a a a a a a a a a a a a a a & 1 \\
\hline 88 & $\mathrm{C} 5$ & 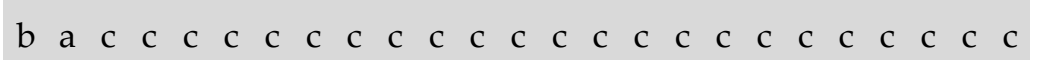 & 2 \\
\hline 89 & $\mathrm{C} 5$ & 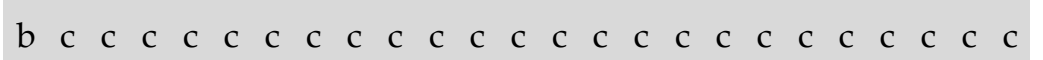 & 1 \\
\hline 90 & $\mathrm{C} 5$ & 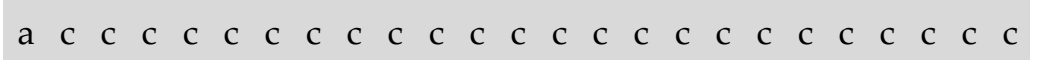 & 1 \\
\hline 92 & $\mathrm{C} 5$ & 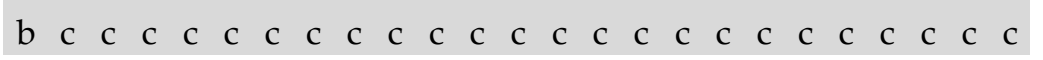 & 1 \\
\hline \multicolumn{2}{|c|}{ Switching Operations } & $\begin{array}{lllllllllllllllllllllllll}0 & 18 & 8 & 0 & 7 & 0 & 3 & 5 & 1 & 1 & 5 & 6 & 4 & 4 & 4 & 2 & 9 & 9 & 4 & 2 & 8 & 1 & 8 & 8 & 3\end{array}$ & 120 \\
\hline
\end{tabular}

Table A3. The phase currents and unbalance factor at the SP level calculated for the considered implementation degrees of the PLBE in the $\mu \mathrm{G}$

\begin{tabular}{|c|c|c|c|c|c|c|c|c|c|c|c|c|}
\hline \multirow{3}{*}{ Hour } & \multicolumn{12}{|c|}{ Implementation degree } \\
\hline & \multicolumn{4}{|c|}{$0 \%$} & \multicolumn{4}{|c|}{$100 \%$} & \multicolumn{4}{|c|}{$17.5 \%$} \\
\hline & $\begin{array}{c}\mathbf{I}_{\mathbf{a}} \\
{[\mathrm{A}]}\end{array}$ & $\begin{array}{c}\mathbf{I b}_{\mathbf{b}} \\
{[\mathrm{A}]}\end{array}$ & $\begin{array}{c}\mathbf{I}_{\mathbf{c}} \\
{[\mathrm{A}]}\end{array}$ & UF & $\begin{array}{c}\mathbf{I} \mathbf{a} \\
{[\mathrm{A}]}\end{array}$ & $\begin{array}{c}\mathbf{I b}_{\mathbf{b}} \\
{[\mathrm{A}]}\end{array}$ & $\begin{array}{c}\mathbf{I}_{\mathbf{c}} \\
{[\mathrm{A}]}\end{array}$ & UF & $\begin{array}{c}\mathbf{I}_{\mathbf{a}} \\
{[\mathrm{A}]}\end{array}$ & $\begin{array}{c}\mathbf{I} \mathbf{b} \\
{[\mathbf{A}]}\end{array}$ & $\begin{array}{c}\mathbf{I}_{\mathbf{c}} \\
{[\mathrm{A}]}\end{array}$ & UF \\
\hline 1 & 14.9 & 51.3 & 20.0 & 1.29 & 28.3 & 28.2 & 28.2 & 1.00001 & 28.5 & 26.5 & 29.8 & 1.027 \\
\hline 2 & 14.1 & 48.9 & 19.1 & 1.29 & 27.0 & 26.9 & 26.9 & 1.00001 & 25.1 & 26.4 & 29.3 & 1.004 \\
\hline 3 & 13.3 & 45.8 & 18.2 & 1.29 & 25.4 & 25.4 & 25.4 & 1.00001 & 23.5 & 25.0 & 27.7 & 1.004 \\
\hline 4 & 13.5 & 46.5 & 17.9 & 1.30 & 25.7 & 25.5 & 25.5 & 1.00001 & 23.8 & 25.3 & 27.6 & 1.004 \\
\hline 5 & 13.7 & 46.0 & 18.4 & 1.28 & 25.6 & 25.7 & 25.7 & 1.00001 & 23.8 & 25.4 & 27.7 & 1.004 \\
\hline 6 & 12.5 & 37.9 & 17.4 & 1.23 & 22.3 & 22.4 & 22.3 & 1.00001 & 21.0 & 22.2 & 23.7 & 1.002 \\
\hline 7 & 16.9 & 43.5 & 20.0 & 1.18 & 26.5 & 26.4 & 26.4 & 1.00000 & 24.9 & 26.5 & 28.0 & 1.002 \\
\hline 8 & 19.7 & 47.5 & 21.5 & 1.17 & 29.2 & 29.0 & 29.3 & 1.00001 & 28.0 & 30.0 & 29.5 & 1.001 \\
\hline 9 & 19.9 & 52.7 & 22.5 & 1.20 & 31.1 & 31.3 & 31.2 & 1.00001 & 29.5 & 31.0 & 33.2 & 1.002 \\
\hline
\end{tabular}




\begin{tabular}{lllllllllllll}
$\mathbf{1 0}$ & 18.2 & 56.7 & 22.3 & 1.26 & 31.9 & 31.9 & 31.7 & 1.00000 & 30.3 & 31.3 & 33.9 & 1.002 \\
$\mathbf{1 1}$ & 19.4 & 65.7 & 23.9 & 1.30 & 35.6 & 35.4 & 35.7 & 1.00000 & 32.7 & 35.3 & 38.7 & 1.004 \\
$\mathbf{1 2}$ & 17.6 & 61.8 & 21.1 & 1.33 & 32.9 & 32.8 & 32.8 & 1.00000 & 30.8 & 31.7 & 35.9 & 1.004 \\
$\mathbf{1 3}$ & 18.1 & 65.8 & 22.0 & 1.35 & 34.4 & 34.7 & 34.6 & 1.00000 & 32.3 & 33.5 & 37.9 & 1.005 \\
$\mathbf{1 4}$ & 18.1 & 64.0 & 23.0 & 1.32 & 34.3 & 34.4 & 34.2 & 1.00000 & 32.4 & 33.3 & 37.3 & 1.004 \\
$\mathbf{1 5}$ & 18.1 & 65.1 & 22.9 & 1.33 & 34.5 & 34.6 & 34.7 & 1.00000 & 32.7 & 33.6 & 37.4 & 1.003 \\
$\mathbf{1 6}$ & 16.1 & 57.3 & 21.8 & 1.31 & 31.2 & 31.0 & 31.2 & 1.00000 & 29.2 & 30.6 & 33.7 & 1.003 \\
$\mathbf{1 7}$ & 18.6 & 65.1 & 23.2 & 1.32 & 34.7 & 35.1 & 34.8 & 1.00001 & 33.2 & 33.8 & 37.6 & 1.003 \\
$\mathbf{1 8}$ & 21.8 & 71.8 & 26.7 & 1.29 & 39.1 & 39.3 & 39.1 & 1.00000 & 37.7 & 39.0 & 40.9 & 1.001 \\
$\mathbf{1 9}$ & 21.6 & 63.2 & 26.0 & 1.23 & 36.2 & 36.2 & 36.3 & 1.00001 & 34.4 & 36.3 & 37.9 & 1.002 \\
$\mathbf{2 0}$ & 21.5 & 55.0 & 24.5 & 1.18 & 33.1 & 33.3 & 33.0 & 1.00000 & 32.0 & 32.9 & 34.5 & 1.001 \\
$\mathbf{2 1}$ & 26.0 & 62.9 & 28.1 & 1.17 & 38.1 & 38.4 & 38.3 & 1.00001 & 37.5 & 39.4 & 37.9 & 1.000 \\
$\mathbf{2 2}$ & 28.1 & 74.1 & 33.0 & 1.19 & 44.2 & 43.7 & 44.2 & 1.00001 & 40.1 & 42.6 & 49.4 & 1.008 \\
$\mathbf{2 3}$ & 25.2 & 74.7 & 32.0 & 1.22 & 42.9 & 42.9 & 43.0 & 1.00002 & 40.9 & 42.6 & 45.4 & 1.002 \\
$\mathbf{2 4}$ & 17.3 & 56.3 & 23.9 & 1.25 & 31.7 & 31.9 & 32.1 & 1.00002 & 29.7 & 31.5 & 34.5 & 1.004 \\
\hline
\end{tabular}

Table A4. The hourly power losses without the implementation of the PLBE in the $\mu G$ ( $0 \%$ implementation degree)

\begin{tabular}{cccccc}
\hline Hour & $\begin{array}{c}\Delta \mathbf{P}_{\mathbf{a}} \\
{[\mathbf{k W}]}\end{array}$ & $\begin{array}{c}\Delta \mathbf{P}_{\mathbf{b}} \\
{[\mathbf{k W}]}\end{array}$ & $\begin{array}{c}\Delta \mathbf{P}_{\mathbf{c}} \\
{[\mathbf{k W}]}\end{array}$ & $\begin{array}{c}\Delta \mathbf{P}_{\mathbf{N}} \\
{[\mathbf{k W}]}\end{array}$ & $\begin{array}{c}\Delta \mathbf{P}_{\text {Total }} \\
{[\mathbf{k W}]}\end{array}$ \\
\hline 1 & 0.033 & 0.555 & 0.109 & 0.441 & 1.138 \\
2 & 0.029 & 0.505 & 0.099 & 0.402 & 1.035 \\
3 & 0.026 & 0.446 & 0.089 & 0.355 & 0.916 \\
4 & 0.027 & 0.457 & 0.087 & 0.363 & 0.933 \\
5 & 0.027 & 0.449 & 0.092 & 0.357 & 0.925 \\
6 & 0.023 & 0.314 & 0.081 & 0.252 & 0.670 \\
7 & 0.042 & 0.421 & 0.108 & 0.332 & 0.902 \\
8 & 0.056 & 0.505 & 0.125 & 0.395 & 1.081 \\
9 & 0.057 & 0.605 & 0.137 & 0.474 & 1.273 \\
10 & 0.049 & 0.680 & 0.135 & 0.535 & 1.399 \\
11 & 0.055 & 0.895 & 0.154 & 0.706 & 1.810 \\
12 & 0.046 & 0.791 & 0.121 & 0.622 & 1.579 \\
13 & 0.048 & 0.892 & 0.131 & 0.703 & 1.775 \\
14 & 0.048 & 0.848 & 0.143 & 0.671 & 1.711 \\
15 & 0.048 & 0.875 & 0.142 & 0.691 & 1.757 \\
16 & 0.039 & 0.686 & 0.129 & 0.546 & 1.400 \\
17 & 0.051 & 0.877 & 0.146 & 0.691 & 1.765 \\
18 & 0.070 & 1.069 & 0.193 & 0.842 & 2.174 \\
19 & 0.068 & 0.854 & 0.183 & 0.672 & 1.777 \\
20 & 0.068 & 0.670 & 0.164 & 0.527 & 1.429 \\
21 & 0.099 & 0.882 & 0.214 & 0.693 & 1.888 \\
22 & 0.115 & 1.195 & 0.292 & 0.949 & 2.551 \\
23 & 0.093 & 1.189 & 0.276 & 0.949 & 2.507 \\
24 & 0.044 & 0.675 & 0.155 & 0.542 & 1.415 \\
\hline $\mathbf{k W h}]$ & $\mathbf{1 . 2 6 0}$ & $\mathbf{1 7 . 3 3 5}$ & $\mathbf{3 . 5 0 4}$ & $\mathbf{1 3 . 7 1 2}$ & 35.811 \\
\hline & & & & &
\end{tabular}


Table A5. The hourly power losses for a $100 \%$ implementation degree of the PLBE in the $\mu G$

\begin{tabular}{llllll}
\hline \multirow{2}{*}{ Hour } & $\boldsymbol{\Delta} \mathbf{P}_{\mathbf{a}}$ & $\boldsymbol{\Delta} \mathbf{P}_{\mathbf{b}}$ & $\boldsymbol{\Delta \mathbf { P } _ { \mathbf { c } }}$ & $\boldsymbol{\Delta \mathbf { P } _ { \mathbf { N } }}$ & $\boldsymbol{\Delta \mathbf { P } _ { \text { Total } }}$ \\
& {$[\mathbf{k W}]$} & {$[\mathbf{k W}]$} & {$[\mathbf{k W}]$} & {$[\mathbf{k W}]$} & {$[\mathbf{k W}]$} \\
\hline 1 & 0.120 & 0.143 & 0.146 & 0.021 & 0.431 \\
2 & 0.110 & 0.134 & 0.130 & 0.020 & 0.393 \\
3 & 0.097 & 0.119 & 0.116 & 0.018 & 0.350 \\
4 & 0.116 & 0.118 & 0.103 & 0.019 & 0.356 \\
5 & 0.115 & 0.119 & 0.104 & 0.018 & 0.356 \\
6 & 0.086 & 0.080 & 0.089 & 0.012 & 0.268 \\
7 & 0.121 & 0.130 & 0.110 & 0.025 & 0.387 \\
8 & 0.147 & 0.148 & 0.146 & 0.034 & 0.475 \\
9 & 0.182 & 0.166 & 0.155 & 0.040 & 0.543 \\
10 & 0.182 & 0.176 & 0.162 & 0.032 & 0.551 \\
11 & 0.223 & 0.199 & 0.227 & 0.041 & 0.691 \\
12 & 0.194 & 0.170 & 0.195 & 0.038 & 0.596 \\
13 & 0.176 & 0.226 & 0.217 & 0.044 & 0.663 \\
14 & 0.209 & 0.212 & 0.185 & 0.038 & 0.644 \\
15 & 0.179 & 0.224 & 0.215 & 0.038 & 0.656 \\
16 & 0.172 & 0.154 & 0.175 & 0.028 & 0.528 \\
17 & 0.181 & 0.226 & 0.218 & 0.037 & 0.663 \\
18 & 0.228 & 0.283 & 0.274 & 0.046 & 0.832 \\
19 & 0.199 & 0.241 & 0.233 & 0.041 & 0.715 \\
20 & 0.189 & 0.208 & 0.171 & 0.037 & 0.603 \\
21 & 0.253 & 0.252 & 0.253 & 0.056 & 0.815 \\
22 & 0.332 & 0.297 & 0.364 & 0.063 & 1.056 \\
23 & 0.322 & 0.327 & 0.289 & 0.050 & 0.989 \\
24 & 0.153 & 0.186 & 0.183 & 0.026 & 0.547 \\
$\boldsymbol{\Delta W} \mathbf{W} \mathbf{W h}]$ & $\mathbf{4 . 2 8 7}$ & $\mathbf{4 . 5 3 9}$ & $\mathbf{4 . 4 6 1}$ & $\mathbf{0 . 8 2 0}$ & $\mathbf{1 4 . 1 0 7}$ \\
\hline & & & & &
\end{tabular}

Table A6. The hourly power losses for a $17.5 \%$ implementation degree of the PLBE in the $\mu \mathrm{G}$

\begin{tabular}{llllll}
\hline \multirow{2}{*}{ Hour } & $\begin{array}{l}\Delta \mathbf{P}_{\mathbf{a}} \\
{[\mathbf{k W}]}\end{array}$ & $\begin{array}{l}\Delta \mathbf{P}_{\mathbf{b}} \\
{[\mathbf{k W}]}\end{array}$ & $\begin{array}{l}\Delta \mathbf{P}_{\mathbf{c}} \\
{[\mathbf{k W}]}\end{array}$ & $\begin{array}{l}\Delta \mathbf{P}_{\mathbf{N}} \\
{[\mathbf{k W}]}\end{array}$ & $\begin{array}{l}\Delta \mathbf{P}_{\text {Total }} \\
{[\mathbf{k W}]}\end{array}$ \\
\hline 1 & 0.122 & 0.120 & 0.188 & 0.043 & 0.472 \\
2 & 0.115 & 0.109 & 0.160 & 0.036 & 0.420 \\
3 & 0.100 & 0.097 & 0.144 & 0.032 & 0.373 \\
4 & 0.106 & 0.099 & 0.134 & 0.023 & 0.362 \\
5 & 0.106 & 0.100 & 0.135 & 0.022 & 0.363 \\
6 & 0.082 & 0.077 & 0.099 & 0.016 & 0.275 \\
7 & 0.113 & 0.113 & 0.144 & 0.036 & 0.405 \\
8 & 0.140 & 0.143 & 0.163 & 0.043 & 0.490 \\
9 & 0.157 & 0.153 & 0.200 & 0.050 & 0.560 \\
10 & 0.170 & 0.175 & 0.185 & 0.046 & 0.576 \\
11 & 0.202 & 0.187 & 0.265 & 0.047 & 0.701 \\
12 & 0.181 & 0.151 & 0.230 & 0.044 & 0.607 \\
13 & 0.199 & 0.170 & 0.255 & 0.049 & 0.672 \\
14 & 0.198 & 0.169 & 0.244 & 0.044 & 0.655 \\
15 & 0.203 & 0.172 & 0.248 & 0.045 & 0.667 \\
\hline
\end{tabular}




\begin{tabular}{llllll}
16 & 0.156 & 0.145 & 0.210 & 0.044 & 0.554 \\
17 & 0.206 & 0.174 & 0.250 & 0.044 & 0.676 \\
18 & 0.264 & 0.270 & 0.269 & 0.071 & 0.874 \\
19 & 0.219 & 0.227 & 0.231 & 0.045 & 0.721 \\
20 & 0.184 & 0.180 & 0.220 & 0.062 & 0.645 \\
21 & 0.251 & 0.254 & 0.271 & 0.081 & 0.857 \\
22 & 0.297 & 0.312 & 0.387 & 0.067 & 1.063 \\
23 & 0.296 & 0.287 & 0.389 & 0.097 & 1.069 \\
24 & 0.158 & 0.157 & 0.223 & 0.052 & 0.591 \\
$\Delta$ W[kWh] & $\mathbf{4 . 2 2 2}$ & $\mathbf{4 . 0 4 0}$ & $\mathbf{5 . 2 4 5}$ & $\mathbf{1 . 1 4 0}$ & $\mathbf{1 4 . 6 4 8}$ \\
\hline
\end{tabular}




\section{References}

1. Khalid, M.; Umer Akram; Shafiq, S., Optimal Planning of Multiple Distributed Generating Units and Storage in Active Distribution Networks, IEEE Access 2018, 6, 55234 - 55244.

2. Grigoras, G.; Ivanov, O.; Neagu, B.C.; Pragma K. Smart Metering Based Strategies for Improving Energy Efficiency in Microgrids. In Microgrid Architectures, Control and Protection Methods; Mahdavi Tabatabaei N., Kabalci E., Bizon N., Eds.; Springer-Verlag, Berlin, Germany, 2020, pp. 463-490.

3. Liu, B.; Meng, K.; Dong, Z.; Wong, P. K. C.; Li, X. Load Balancing in Low-voltage Distribution Network via Phase Reconfiguration: An Efficient Sensitivity-based Approach, in IEEE Trans. on Pow. Deliv. 2020, Early Access doi: 10.1109/TPWRD.2020.3022061.

4. Haq, S. U.; Arif, B.; Khan, A.; Ahmed, J. Automatic three phase load balancing system by using fast switching relay in three phase distribution system. Proceedings of the International Conference on Power, Energy and Smart Grid (ICPESG), Mirpur, Pakistan, 2018, pp. 1-6, doi: 10.1109/ICPESG.2018.8384514.

5. Narayanan, K. N.; Umanand, L. A novel active phase router for dynamic load balancing in a three phase microgrid. Proceedings of the 2017 IEEE PES Asia-Pacific Power and Energy Engineering Conference (APPEEC), Bangalore, India, 2017, pp. 1-5, doi: 10.1109/APPEEC.2017.8308922.

6. Homaee, O.; Najafi, A.; Dehghanian, M.; Attar, M.; Falaghi, H. A practical approach for distribution network load balancing by optimal re-phasing of single-phase customers using discrete genetic algorithm. Int. Trans. on Electrical Energy Syst. 2019, 29(5), e2834.

7. Liu, Y.-W.; Rau, S.-H.; Wu, C.-J.; Lee, W.-J. Improvement of Power Quality by Using Advanced ReactivePower Compensation. IEEE Trans. Ind. Appl. 2018, 54, 18-24.

8. Kalesar, B.M. Customers swapping between phases for loss reduction considering daily load profile modelin smart grid. In Proceedings of the CIRED Workshop 2016, Helsinki, Finland, 14-15 June 2016; pp. $1-4$.

9. Jianguo, Z.; Qiuye, S.; Huaguang Z.; Yan, Z. Load balancing and reactive power compensation based on capacitor banks shunt compensation in low voltage distribution networks, Proceedings of the $31^{\text {st }}$ Chinese Control Conference, Hefei, China, 2012, pp. 6681-6686.

10. Arias, J.; Calle, M.; Turizo, D.; Guerrero, J.; Candelo-Becerra, J.E. Historical Load Balance in Distribution Systems Using the Branch and Bound Algorithm. Energies 2019, 12, 1219.

11. Granada Echeverri, M.; Gallego Rendón, R. A.; López Lezama, J. M. Optimal phase balancing planning for loss reduction in distribution systems using a specialized genetic algorithm. Ingeniería y Ciencia 2012, 8(15), 121-140.

12. Al-Kharsan, I. H. A New Strategy for Phase Swapping Load Balancing Relying on a Meta-Heuristic MOGWO Algorithm, J. Mech. Contin. Math. Sci. 2020, 15 (2), 84-102.

13. Mahendran, G.; Govindaraju, C. Flower pollination algorithm for distribution system phase balancing considering variable demand. Microprocessors and Microsystems 2020, 74, 103008.

14. Saffar, A.; Hooshmand, R.; Khodabakhshian, A. A new fuzzy optimal reconfiguration of distribution systems for loss reduction and load balancing using ant colony search-based algorithm. App. Soft Comp. 2011, 11(5), 4021-4028.

15. Hooshmand, R.; Soltani, S. H. Simultaneous optimization of phase balancing and reconfiguration in distribution networks using BF-NM algorithm. Int. J. of Elec. Pow. E En. Syst. 2012, 41(1), 76-86.

16. Olek, B.; Wierzbowski, M. Local energy balancing and ancillary services in low-voltage networks with distributed generation, energy storage, and active loads. IEEE Trans. on Ind. Electr. 2014, 62 (4), 2499-2508.

17. Kikhavani, M. R.; Hajizadeh, A.; Shahirinia, A. Charging coordination and load balancing of plug-in electric vehicles in unbalanced low-voltage distribution systems, IET Gen., Transm. E Distrib. 2020, 14(3), 389-399, doi: 10.1049/iet-gtd.2019.0397.

18. Weckx, S.; Driesen J. Load balancing with EV chargers and PV inverters in unbalanced distribution grids. IEEE Trans. on Sust. En. 2015, 6(2), 635-643.

19. Evzelman, M.; Ur Rehman, M. M.; Hathaway, K.; Zane, R.; Costinett D.; Maksimovic, D. Active balancing system for electric vehicles with incorporated low-voltage bus. IEEE Trans. on Pow. Electr. 2015, 31 (11), 7887-7895, doi: 10.1109/TPEL.2015.2513432.

20. Faessler, B.; Schuler, M.; Preißinger, M.; Kepplinger, P. Battery Storage Systems as Grid-Balancing Measure in Low-Voltage Distribution Grids with Distributed Generation. Energies 2017, 10, 2161. 
21. De Carne, G.; Buticchi, G.; Liserre, M.; Yoon, C.; Blaabjerg, F. Voltage and current balancing in low and medium voltage grid by means of smart transformer. Proceedings of the IEEE Power \& Energy Society General Meeting, 2015, Denver, USA, pp. 1-5.

22. Pasdar, A.; Mehne, H. H. Intelligent three-phase current balancing technique for single-phase load based on smart metering. Int. J. of Elec. Pow. E En. Syst. 2011, 33(3), 693-698.

23. SinePuls, Single Phase STS Prepaid Meter, Available online: https://sinepulse.com/sites/default/files/smartmeter/SP_SINGLE_PHASE_STS_PREPAID_METER.pdf (accessed on 21 November 2020).

24. Londian, Smart Prepaid Meter, Available online: http://www.londian.com.cn/en/index.php?s=/cms/209 (accessed on 21 November 2020).

25. Novatek-Electro, Universal Automatic Electronic Phase Switch Pef-319, Available online: https://novatekelectro.com/en/products/phase-selector-switch/universal-automatic-electronic-phase-switch-pef-301.html pdf (accessed on 21 November 2020).

26. Yongxia, L.; Yulei G. Design of Three Phase Load Unbalance Automatic Regulating System for Low Voltage Power Distribution Grids, MATEC Web of Conferences, 2018, 173, doi.org/10.1051/matecconf/ 201817302040, SMIMA 2018.

27. Haq, S.U.; Arif, B.; Khan, A.; Ahmed, J. Automatic three phase load balancing system by using fast switching relay in three phase distribution system, Proceedings of the $1^{\text {st }}$ International Conference on Power, Energy and Smart Grid (ICPESG), 2018, Mirpur, Pakistan, 1-6.

28. Iyappan, M.; Karpagam, M.; Raviram, P. Automatic Load Sharing In Industrial Plant With Monitoring System Using Microcontroller, Int. J. of App. Eng. Res. 2015, 10 (64), 114-120.

29. Ofualagba, G.; Udoha, E.E. Design and Simulation of Automatic Phase Selector and Changeover Switch for 3-Phase Supply, Int. J. of Nov. Res. in Elec. and Mech. Eng. 2017, 4(2), 28-35.

30. Rashid, A. T.; Rashid, M. T. Design and Implementation of Load Balancing System for a Smart Home, Proceedings of the International Scientific Conference for Renewable Energy (ISCRE' 2018), Basrah, Iraq, March 2018, pp. 1-6.

31. Shakeel, M. O. B.; Jaffar, S. A., Ali, M. F.; Zaidi, S. S. LV Three Phase Automatic Load Balancing System, International Conference on Energy, Environment and Sustainable Development 2016 (EESD 2016).

32. Bao, G.; Ke, S. Load Transfer Device for Solving a Three-Phase Unbalance Problem Under a Low-Voltage Distribution Network. Energies 2019, 12, 2842.

33. Fränti, P.; Sieranoja, S. How Much Can K-Means Be Improved by Using Better Initialization and Repeats? Pattern Recognition 2019, 93, 95-112.

34. Clustering in Machine Learning. K-means Advantages and Disadvantages, Available online: https://developers.google.com/machine-learning/clustering/algorithm/advantages-disadvantages (accessed on 21 November 2020).

35. Grigoras, G.; Neagu, B.-C.; Smart Meter Data-Based Three-Stage Algorithm to Calculate Power and Energy Losses in Low Voltage Distribution Networks. Energies 2019, 12, 3008.

36. Romanian Energy Regulatory Authority. Normative for the Design of the Electrical Networks of Public Distribution-PE 132/2003; 2003. Available online: https://www.anre.ro/ro/legislatie/normetehnice/normative-tehnice-energetice-nte (accessed on 21 November 2020).

37. Noroc L.; Grigoras G. Clustering-based consumers' selection to optimal placement of the phase load balancing devices. Proceedings of the $11^{\text {th }}$ Int. Conf. and Exposition on Electrical and Power Engineering, Iasi, Romania, 22-23 October 2020, pp. 1-4

38. Sinaga, K.; Yang, M.S. Unsupervised K-Means Clustering Algorithm Unsupervised K-Means Clustering Algorithm, IEEE Access 2020, 8, 80716 - 80727.

39. Rousseeuw, P.; Silhouettes: A graphical aid to the interpretation and validation of cluster analysis, Journal of Computational and Applied Mathematics 1987, 20, 53-65

40. Grigoras, G.; Neagu, B.C.; Gavrilas, M.; Tristiu, I.; Bulac, C; Optimal Phase Load Balancing in Low Voltage Distribution Networks Using a Smart Meter Data-Based Algorithm. Mathematics 2020, 8, 549.

41. Ivanov, O.; Grigoras, G.; Neagu, B.C. Smart Metering based Approaches to Solve the Load Phase Balancing Problem in Low Voltage Distribution Networks. In Proceedings of the International Symposium on Fundamentals of Electrical Engineering (ISFEE), Bucharest, Romania, 1-3 November 2018; pp. 1-6.

42. Ivanov, O.; Neagu, B.C.; Gavrilas, M.; Grigoras, G.; Sfintes, C. Phase Load Balancing in Low Voltage Distribution Networks Using Metaheuristic Algorithms. In Proceedings of the International Conference on Electromechanical and Energy Systems (SIELMEN), Craiova, Romania, 9-11 October 2019; pp. 1-6 